\title{
Strategic benefits of low fit brand extensions: When and why?
}

\author{
HaeEun Helen Chun \\ Cornell University \\ C. Whan Park ${ }^{1}$ \\ University of Southern California \\ Andreas B. Eisingerich \\ Imperial College London \\ Deborah J. MacInnis \\ University of Southern California
}

\begin{abstract}
Brand extensions have the potential to both enhance liking of the brand extension and induce positive spillover effects on the parent brand. Such dual outcomes enhance the brand's growth potential. We propose and empirically demonstrate that three variables endemic to any brand extension decision (brand reputation, brand extension fit, brand extension benefit innovativeness) jointly impact these positive outcomes. For strong reputation brands, these dual outcomes are maximized when the brand extension is low in fit and offers innovative benefits because low fit motivates consumers to process innovative brand extension information more deeply. For weak reputation brands, these effects are maximized when the brand extension is high in fit and offers innovative benefits because high fit strengthens consumers' trust in the weak brand's ability to deliver promoted benefits. The results suggest two distinct brand growth strategies for strong and weak reputation brands respectively.
\end{abstract}

Keywords: Brand extensions; Spillover effects; Brand management; Brand schema; Brand associations

\section{Introduction}

Brand extensions are important strategic devices that allow a firm to grow by leveraging its current customer base and parent brand image. Specifically, by linking the new product to a known parent, they leverage parent brand knowledge to quickly and efficiently establish the new product's identity (Aaker \& Keller, 1990; Broniarczyk \& Alba, 1994; Park, Milberg, \& Lawson, 1991; Smith \& Park, 1992). They also have the potential to induce positive spillover effects on the parent brand by (1) adding new associations to the parent brand schema, (2) enhancing consumers' evaluations of the parent brand, and (3) increasing consumers' receptivity to future brand extensions offered by the firm.

These dual outcomes (favorable brand extension evaluations and positive spillover effects on the parent brand) have strong strategic value and they are potentially transformative to the firm given their synergistic effects on the firm's

1 Corresponding author at: Department of Marketing, Marshall School of Business, University of Southern California, Los Angeles, CA 90089-0808, USA.

E-mail addresses: hc633@cornell.edu (H.H. Chun), choong@marshall.usc.edu (C.W. Park), a.eisingerich@imperial.ac.uk (A.B. Eisingerich), macinnis@usc.edu (D.J. Maclnnis). 
growth and revenue. Specifically, by achieving these combined outcomes firms can expand their current market base and revenue (through favorably evaluated brand extensions) and expand their future markets and revenue (by associations added to the parent brand and consumers' acceptance of future brand extensions), while also solidifying their current market base and revenue (by increasing parent brand liking). Given the importance of these combined outcomes, it is critical to understand the factors directly under the control of firms that may induce them.

We contribute to the literature theoretically and pragmatically by examining the joint impact of three factors that are endemic to any brand extension decision (brand reputation, brand extension fit, brand extension benefit innovativeness) on both brand extension evaluation and spillover effects on the parent brand. Brand reputation is defined as the extent to which consumers respect the parent brand and hold it in high regard. Fit is defined as the extent to which the image and associations linked to the parent brand and the extension product are similar and go well with the extension product (Broniarczyk \& Alba, 1994; Park et al., 1991). In line with prior work, this definition of fit goes beyond a traditional definition centered on a feature- based fit at the product class level and accommodates broader associations that tap into a relational match between the brand and the extension product.

Innovative benefits map the properties of innovative or creative ideas (Goldenberg, Mazursky, \& Solomon, 1999; Moreau \& Dahl, 2005), which conceptualizes innovativeness in terms of two critical factors: novelty and usefulness (functionality or appropriateness; Burroughs, Dahl, Moreau, Chattopadhyay, \& Gorn, 2011; Sternberg \& Lubart, 1999). Although novelty is often associated with innovativeness, usefulness is also an important component of the innovativeness construct (Moreau \& Dahl, 2005). Both theoretical ideas (e.g., Sternberg \& Lubart, 1999) and empirical findings underscore the importance of both dimensions as components of innovativeness (e.g., Goldenberg et al., 1999; Moreau \& Dahl, 2005; Sellier \& Dahl, 2011). Accordingly, we define benefit innovativeness as the extent to which the benefits of the brand extension are novel and useful to consumers. The opposite of innovative benefits are ordinary benefits, which are limited in novelty and less differentially useful to consumers since they are common to brands in the product category.

While parent brand reputation, fit, and benefit innovativeness are natural parameters for consideration by managers who are responsible for brand extension decisions and endemic to any brand extension decision, prior research has not examined their joint impact, let alone their joint impact on the two aforementioned growth drivers (i.e., favorable brand extension evaluations and positive spillover effects).

We make a unique and significant contribution by examining the joint effects of three variables that are under the control of firms on both brand extension evaluations and three indicators of positive spillover effects (novel associations added to the parent brand, favorable parent brand evaluations, and acceptance of future extensions to the parent brand). We propose and demonstrate that when brand reputation is strong, brands enjoy favorable brand extension evaluations and the most positive spillover effects when a brand offers innovative benefits and extends to a low fit category. In contrast, when brand reputation is weak, brands enjoy the most favorable brand extension evaluations and the most positive spillover effects when a brand offers innovative benefits and extends to a high fit category. These effects are replicated for functional (Study 1), symbolic (Study 2), and experiential brands (Study 3). As such, an important key 
takeaway from our work is that positive growth is greatest when an extension offers innovative benefits. Yet whether high fit or low fit extensions maximize growth potential depends on whether the brand reputation is weak or strong.

We also contribute to the literature on spillover effects. Past research has indicated spillover effects by (a) strengthened parent brand associations measured by categorization speed, recognition, and recall (Morrin, 1999), (b) changes in existing parent brand beliefs (John, Loken, \& Joiner, 1998; Loken \& John, 1993; Milberg, Park, \& McCarthy, 1997), (c) extension evaluations (Aaker \& Keller, 1990), or (d) the strength of parent beliefs and the favorability of parent brand evaluations (Ahluwalia \& Gürhan-Canli, 2000). Balachander and Ghose (2003) measured the spillover effect with (e) a parent brand choice as a result of (the advertising of) brand extensions. Sullivan (1990) also analyzed spillover effects with (f) a depreciation rate in the used car market as a result of an extension. Notably, prior research has not examined the collective basket of spillover effects linked to brand growth potential (i.e., novel associations added to the parent brand, favorable parent brand evaluations, and acceptance of future extensions to the parent brand).

Findings from our studies are both significant and novel to the literature, yet they reinforce recent research. Barone and Jewell (2013) find that reputable innovative brands can employ nonnormative strategies without paying the penalty associated with using atypical strategies and indeed are rewarded for utilizing such approaches. Our findings also coincide with anecdotal evidence from the marketplace. BMW's extension from automobiles to skateboards, Virgin's extension from music records to airlines, and Red Bull's extension from an energy drink to its own Formula 1 racing team illustrate the success of strong reputation brands' extension to low fit categories.

Notably, the notion that low fit brand extensions can sometimes induce positive outcomes to the extension and parent brand is not inconsistent with prior research. Ahluwalia and Gürhan-Canli (2000) found that positive (vs. negative) information about low fit extensions induces positive spillover effects (which they call an enhancement effect) because positive information about the low fit extensions is more diagnostic than negative information. Additional research finds that the impact of fit is more malleable than previously thought. Malleability depends on a variety of factors in the decision context including the presence of attribute information (Klink \& Smith, 2001) or visual cues (Meyvis, Goldsmith, \& Dhar, 2012), levels of involvement and mood (Barone, 2005; Maoz \& Tybout, 2002), holistic versus analytic thinking (Monga \& John, 2010), construal levels (Ahluwalia, 2008; Kim \& John, 2008), feelings of control (Cutright, Bettman, \& Fitzsimons, 2013), and competitive context (Milberg, Sinn, \& Goodstein, 2010; Milberg, Goodstein, Sinn, Cuneo, \& Epstein, 2013). For example, Klink and Smith (2001) found that low fit extensions were evaluated favorably when consumers were given attribute information about the extension.

The present paper is organized as follows. We first develop a set of predictions about brand extension evaluations and spillover effects on the parent brand under varying conditions of brand reputation, extension fit, and extension benefit innovativeness. We then describe three studies that test and support our predictions. We conclude with a set of managerial implications and future research directions.

\section{Theory and hypothesized effects}

The Introduction argues that brands are poised for growth when they create both favorable brand extension 
evaluations and positive spillover effects on the parent brand. We specify here what factors induce these dual outcomes and why. We predict that when brand reputation is strong, the dual effects of positive brand extension evaluations and positive spillover effects are maximized when the brand offers a low fit extension with innovative benefits (H1) because low fit motivates consumers to process innovative brand extension information more deeply while the brand's strong reputation provides trust in the delivery of such benefits $(\mathrm{H} 2)$. In contrast, when brand reputation is weak, the dual effects of positive brand extension evaluations and positive spillover effects are greatest when a high fit extension has innovative benefits (H3) because high fit strengthens consumers' trust in the weak brand's ability to deliver promoted benefits (H4). We explain our logic below.

\section{Brand extension evaluations and extension spillover effects when brand reputation is strong}

We first address consumers' brand extension evaluations, then follow with thoughts regarding spillover effects. Spillover effects are not identical to brand extension evaluations since they involve a structural change to one's global understanding of the parent brand. Such understanding could involve considerably more than favorable brand extension evaluations.

\section{Brand extension evaluations for strong reputation brands}

When brand reputation is strong (vs. weak), we expect that consumers trust the brand and hence are more willing to begin or continue a relationship with it (Aaker, Garbinsky, \& Vohs, 2012; Park et al., 2013). Indeed, we argue that strong brand trust and a willingness to maintain a brand relationship may enhance consumers' openness to the brand's innovative benefits, even when fit is low. Innovative benefits are both interesting and useful in the extension's consumption context; hence information about these benefits is diagnostic in judging the extension's ability to satisfy consumers' needs (Huffman \& Houston, 1993). Thus, regardless of extension fit, we expect that consumers will pay attention to and favorably evaluate extensions from strong reputation brands that offer innovative benefits. The fact that consumers may downplay fit in brand extension judgments is consistent with Klink and Smith (2001) who found that the impact of fit on brand extension evaluations diminishes when consumers are provided with attribute information about the brand extension. It is also consistent with the previously described research showing that the effect of fit depends on a number of contextual factors (here brand reputation and benefit innovativeness). Thus, we expect that when brand reputation is strong, consumers will like brand extensions with innovative benefits more than those with ordinary benefits, regardless of fit.

Notably though, the process by which consumers form evaluations of high vs. low fit brand extensions may differ. High fit extensions with innovative benefits have consumer appeal because existing beliefs and/or liking of the parent brand are easily transferred to the high fit extension (e.g., Aaker \& Keller, 1990; Boush \& Loken, 1991). The easy accommodation of the high fit extension into the parent brand schema makes evaluations of the brand extension favorable. On the other hand, low fit brand extensions with innovative benefits violate consumers' category expectations, which makes benefits surprising and attention getting (Schützwohl, 1998), enhancing consumers' desire to resolve and remove incongruity by diligently processing unexpected information (Meyers-Levy \& Tybout, 1989). Deeper processing of these benefits allows consumers to appreciate how the strong reputation brand's innovative benefits might address their needs. Accordingly, 
high and low fit brand extensions with innovative benefits should have similarly favorable brand extension evaluations, even if for different reasons.

\section{Spillover effects on strong reputation parent brands}

Since consumers have considerable trust in a strong reputation brand (and subsequently in its extension), they may favorably revise their understanding of the parent brand when its extensions offer innovative (novel and useful) benefits. We predict that positive spillover effects to a strong reputation brand will be greatest when the brand offers innovative benefits to its low fit extensions. This is so because low fit induces greater motivation to process the brand extension's benefits. Thus, a strong reputation gives a brand more leverage to successfully move into different low-fitting categories. Innovative benefits to high fit extensions might positively reinforce the brand's image (Park et al., 1991); but they do not violate category expectations and therefore are less surprising. As such, consumers may be less motivated to deeply process these benefits and update the parent brand schema.

We predict these positive outcomes for low fit brands with innovative benefits for each of the indicators of the spillover effects we examine in this paper. First, when brand reputation is strong, low fit is expected to foster consumers' willingness to accommodate the brand extension's innovative benefits into the strong reputation brand's schema through greater processing of the innovative benefits. Brand schema revision will be greater for a low fit (vs. high) fit extension given the smaller overlap between the brand and its extension category. By revising the brand schema to accommodate new low fit benefits, consumers are left with a broader understanding of the brand (Sujan \& Bettman, 1989). These ideas are consistent with Barsalou's (1991) ad hoc categorization view, which suggests that seemingly unrelated and dissimilar objects/concepts (e.g., a parent brand, a low fit extension, and future low fit extensions) can be conceptualized as belonging to a higher-order concept. They are also consistent with results by Park, Jun, and Shocker (1996) who found that consumers exposed to a low fit co-branded extension (e.g., Slimfast introducing "Slimfast chocolate cake mix by Godiva") modified and substantially expanded their understanding of the parent brand (e.g., Slimfast as a low calorie brand); they incorporated the attribute information of its co-branded extension (e.g., Godiva's superior taste) into the parent brand schema (e.g., Slimfast as a low calorie brand with good taste).

Second, consumers' parent brand evaluations of a strong reputation brand should be enhanced when fit is low and benefits are innovative since the strong reputation brand is now relevant to them in new and useful ways, in light of its innovative benefits and consumers' deeper processing of them. Consumers' updated brand beliefs are thus expected to enhance evaluations of the parent brand.

Third, consumers' abilities to accommodate future low fit extensions to the parent brand should be enhanced because the innovative benefits of the low fit extension are now incorporated into the parent brand schema. Because the low fit extension creates a broader set of associations with the parent brand, it is likely that other low fit extensions will be seen as closer to the parent brand in fit and thus seem more acceptable.

Even when brand reputation is strong, positive spillover effects are not anticipated when the brand extension has ordinary (vs. innovative) benefits. Consumers should be less motivated to process information about brand extensions 
with ordinary benefits. Thus, they will not see the relevance of low fit extensions. Nor will the ordinary nature of the brand extension motivate consumers to change their parent brand schema.

In sum, we expect that when brand reputation is strong, consumers have equally positive evaluations of low and high fit brand extensions with innovative benefits. But positive spillover effects (broader understanding of the parent brand through added novel associations, more positive evaluations of the parent brand, and greater acceptance of future low fit brand extensions) are greatest when the brand extension is low in fit and has innovative benefits (than in under any other fit/benefit condition). Thus:

H1. For a strong reputation brand, the dual effects of positive brand extension evaluations and positive spillover effects on the parent brand are maximized when the brand offers a low fit extension with innovative benefits.

\section{Mediating process influencing positive spillover effects for strong reputation brands}

$\mathrm{H} 1$ is premised on the idea that consumers are more motivated to deeply process the benefits of the strong reputation brand's extension when fit is low (vs. high). Specifically, (a) deeper processing of the innovative benefits of the low fit extension and (b) acceptance of these benefits in light of the brand's strong reputation changes consumers' understanding of the brand. This change makes the parent brand seem both different from before and also more likable. We therefore predict that motivation to process extension benefits drives these outcomes.

H2. For a strong reputation brand, positive spillover effects from low fit extensions with innovative benefits are mediated by enhanced motivation to process information about the low fit brand's innovative benefits.

We expect consumers will react differently when brand reputation is weak.

\section{Brand extension evaluations and extension spillover effects when brand reputation is weak}

\section{Brand extension evaluations for weak reputation brands}

When brand reputation is weak, consumers' trust in the brand's ability to deliver innovative benefits is low. Without strong brand trust, consumers may react more favorably to high (vs. low) fit extensions with innovative benefits. High fit allows consumers to align the brand extension with the brand's existing core competence and other key associations (e.g., Aaker \& Keller, 1990). This is expected since the brand and its high fit extension share common features. Therefore, when brand reputation is weak, consumers are expected to evaluate a high fit extension with innovative benefits most favorably because they can transfer the core competence or key associations of the parent brand to high fit extension and accept the high extensions' innovative benefits more readily.

In contrast to high fit extensions, low fit extensions do not share significant common features with the parent brand. Because trust in the weak reputation brand is low, consumers neither readily accept the innovative benefits of the low fit extension, nor transfer the core competence or key associations of the parent brand to the low fit extension. Accordingly, when brand reputation is weak, high fit extensions with innovative benefits will be evaluated more favorably than low fit extensions. Both high and low fit extensions with ordinary benefits should be evaluated less favorably than those with innovative benefits because the benefits are less novel and useful to consumers. Low fit extensions with ordinary benefits 
are likely to be evaluated particularly unfavorably because low fit, coupled with a weak brand reputation, reduces trust that the brand can deliver on even ordinary benefits. In sum, when brand reputation is weak, high fit extensions with innovative benefits will be evaluated most favorably than other fit/benefit conditions.

\section{Spillover effects on weak reputation parent brands}

When brand reputation is weak, we also expect that spillover effects are greatest for high fit extensions with innovative benefits. Specifically, since the brand and its high fit extension share common features, consumers trust the high (vs. low) fit parent brand's ability to deliver the promised extension benefits. Trust from high fit makes consumers more willing to add new (innovative benefit) associations to the high (vs. low) fit parent brand. When fit is low, overlap between the parent brand and its low fit extensions is limited, further exacerbating trust in a weak reputation brand.

In addition, we do not expect that the high fit extension will induce positive spillover effects when a weak reputation brand offers ordinary (vs. innovative) benefits. High fit coupled with ordinary benefits is not expected to change the parent brand schema given the high overlap between the brand extension and parent brand. Analogously, low fit extensions with ordinary benefits should not induce positive spillover effects because trust associated with a weak reputation brand is further compromised by the absence of the shared competence (low fit) and ordinary benefits.

Based on the logic above, we predict that:

H3. For a weak reputation brand, the dual effects of positive brand extension evaluations and positive spillover effects are greatest when the brand offers a high fit extension with innovative benefits than in under any other fit/benefit condition.

\section{Mediating process influencing positive spillover effects for weak reputation brands}

The logic driving H3 is premised on the idea that when brand reputation is weak, consumers have less trust in the low fit brand's ability to deliver innovative benefits. High fit provides diagnostic information about brand's credibility, which increases consumers' trust (and counteracts effects of the weak reputation brand), while innovative benefits add new parent brand associations. In sum, when brand reputation is weak, consumers' trust in the brand's ability to deliver innovative benefits mediates the relationship between fit and spillover effects.

H4. For a weak reputation brand, positive spillover effects from high fit extensions with innovative benefits are mediated by trust in the parent brand's ability to deliver promised extension benefits.

\section{Study 1}

\section{Method}

Study 1 tests $\mathrm{H} 1-\mathrm{H} 4$ using Lenovo and Acer as strong and weak reputation brands respectively. Both have a functional brand image in the consumer electronics category. Study 1 used a 2 (strong vs. weak brand reputation) x 2 (high vs. low fit) $\times 2$ (innovative vs. ordinary benefits) between-subjects experimental design with one baseline control condition for

each brand (see Fig. 1). The two baseline control conditions did not include any brand extension information or ask questions pertinent to brand extension judgments. 


\section{Strong and weak parent brands}

We selected Lenovo and Acer as the focal parents based on a pretest $(N=51)$ that indicated that the brands differed in reputation; Lenovo's reputation was viewed as stronger than Acer's (Table 1 shows indicators of all constructs used in the paper and their scale reliabilities). The brands were also pretested to be similar on other factors that might affect brand extension evaluations and spillover effects. Detailed pretest results are reported in the web appendix.

\section{High and low fit brand extensions}

Portable navigation systems and bed sheets were selected as high and low fit extension categories (see Fig. 1), based on a pretest $(\mathrm{N}=51)$ that identified them as varying in fit with the parent brands. We assessed fit with a 2-item 9-point scale that tapped into the relational match between the brand extension and the parent brand (see Table 1) as well as the overall similarity between the extension and the parent brand ("What is the global similarity between Lenovo and portable navigation systems?"). We also measured fit in terms of the perceived skill of the parent brand to offer a product in the extension category ("Would the people, facilities, and skills used in making laptops be helpful if Lenovo were to make portable navigation systems?" (Völckner \& Sattler, 2006). These multiple measures of fit yielded results that did not differ from the 2-item scale reported in Table 1 . Thus, we use the 2-item scale in all three studies.

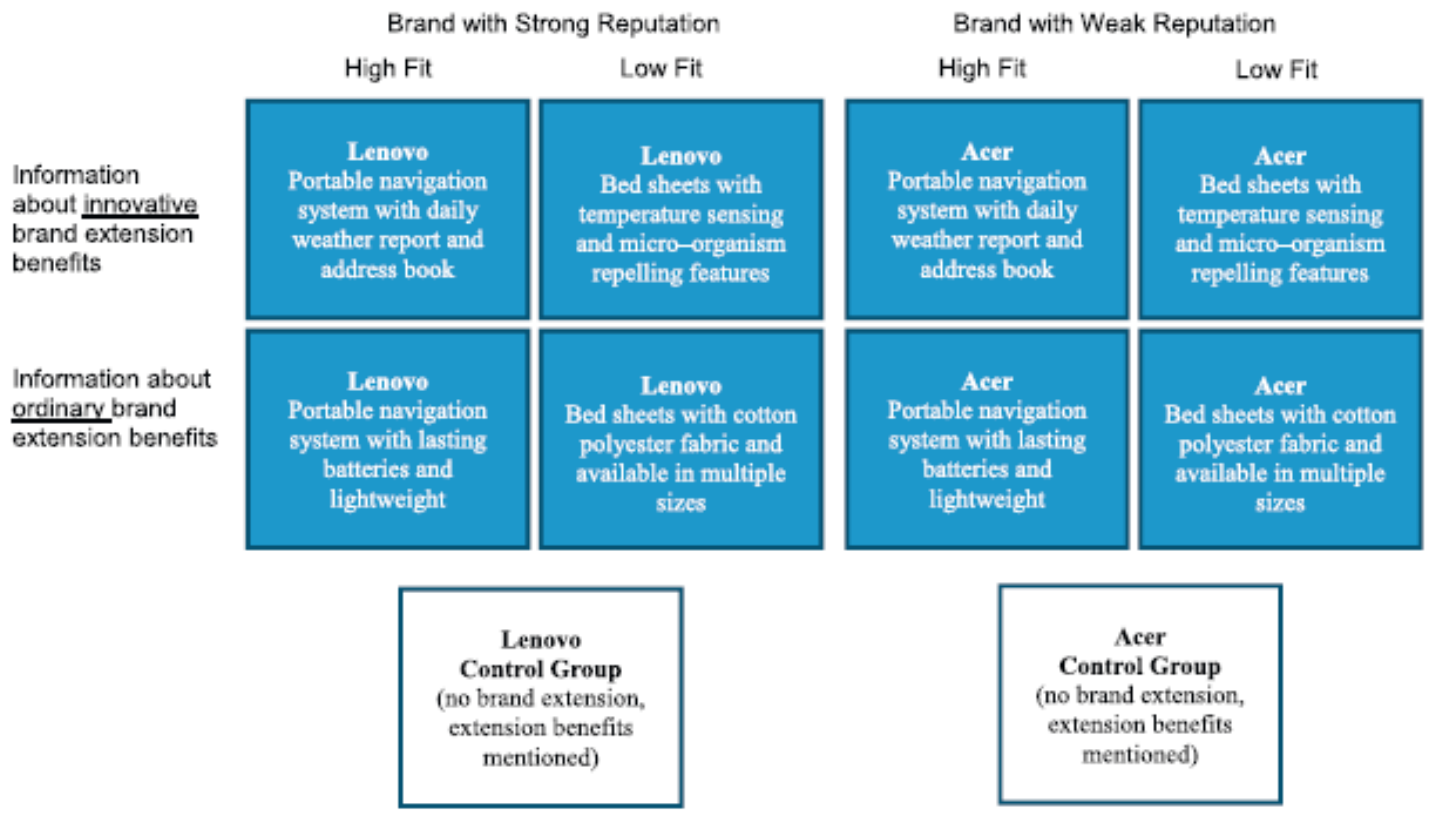

Fig. 1. Study 1: Experimental conditions. 


\begin{tabular}{|c|c|c|c|c|}
\hline Measures & Items & Study 1 & Study 2 & Study 3 \\
\hline Brand reputation & $\begin{array}{l}\text { What is your opinion of [brand name]'s brand reputation? } \\
\text { How much respect do you have for the [brand name] brand? } \\
\text { Anchors }(1)=\text { very poor/very low, }(9) \text { = very good/very high }\end{array}$ & $.97^{\mathrm{a}}$ & $.76^{\mathrm{a}}$ & $.93^{\mathrm{a}}$ \\
\hline Extension surprise & $\begin{array}{l}\text { How sumprised are you to hear that [brand name] is introducing [extension product]? } \\
\text { How unexpected is it for [brand name] to introduce [extension product]? } \\
\text { How curious are you about [brand name] [extension product]? } \\
\text { Anchors }(1)=\text { not at all surprised/unexpected/curious, }(9)=\text { very surprised/unexpected/curious }\end{array}$ & $.98^{b}$ & $.98^{\mathrm{b}}$ & $.96^{b}$ \\
\hline Brand extension evaluations & $\begin{array}{l}\text { Please rate your overall opinion of [brand name]'s [extension product] on the following scale. } \\
\text { Anchors }(1)=\text { dislike/unfavorable, }(9)=\text { like/favorable }\end{array}$ & $.94^{\mathrm{a}}$ & $.98^{\mathrm{a}}$ & $.96^{\mathrm{a}}$ \\
\hline Parent brand evaluations & $\begin{array}{l}\text { Please rate your opinion of the [brand name] brand on the following scale. } \\
\text { Anchors }(1)=\text { dislike/unfavorable, }(9)=\text { like/favorable }\end{array}$ & $.95^{\mathrm{a}}$ & $.73^{\mathrm{a}}$ & $.94^{\mathrm{a}}$ \\
\hline Motivation to process & $\begin{array}{l}\text { How motivated were you to read the description of [brand name]'s [extension product]? } \\
\text { How eager were you to read the description of [brand name]'s [extension product]? } \\
\text { How attentive were you to the description of [brand name]'s [extension product]? } \\
\text { Anchors }(1) \text { = not at all motivated/eager/attentive, }(9) \text { = very motivated/eager/attentive }\end{array}$ & $.96^{b}$ & $.84^{\mathrm{b}}$ & $.79^{b}$ \\
\hline Benefit innovativeness & $\begin{array}{l}\text { How new are the benefits of [brand name]'s [extension product]? } \\
\text { How useful are the benefits of [brand name]' [extension product]? } \\
\text { How innovative are the benefits of [brand name]'s [extension product]? } \\
\text { Anchors }(1)=\text { not at all new/useful/innovative, }(9) \text { = very new/useful/innovative }\end{array}$ & $.92^{\mathrm{b}}$ & $.96^{\mathrm{b}}$ & $.97^{\mathrm{b}}$ \\
\hline Trust in brand delivering extension benefits & $\begin{array}{l}\text { To what extent do you think [brand name] has the ability to actually deliver the promised extension } \\
\text { benefits in a reliable manner? } \\
\text { To what extent do you have confidence in the ability of the [brand name] brand to consistently } \\
\text { deliver the promised extension benefits to customers? } \\
\text { Anchors (1) = not at all, (9) = very much }\end{array}$ & $.86^{\mathrm{a}}$ & $.91^{\mathrm{a}}$ & $.90^{\mathrm{a}}$ \\
\hline Core parent brand associations & $\begin{array}{l}\text { When I hear the name [brand name] what comes to mind is [e.g., performance, etc.]. } \\
\text { Anchors }(1)=\text { strongly disagree, }(9)=\text { strongly agree }\end{array}$ & $.88^{\mathrm{b}}$ & $.90^{\mathrm{a}}$ & na \\
\hline Novel parent brand associations & $\begin{array}{l}\text { When I hear the name [brand name] what comes to mind is [e.g., comfort, etc.]. } \\
\text { Anchors }(1)=\text { strongly disagree, }(9)=\text { strongly agree }\end{array}$ & $.92^{\mathrm{b}}$ & $.72^{\mathrm{a}}$ & $.70^{\mathrm{a}}$ \\
\hline Acceptance of future low fit extensions & $\begin{array}{l}\text { If [brand name] were to introduce new products, how acceptable would each of the following } \\
\text { products be to you? } \\
\text { Anchors }(1)=\text { not at all acceptable, }(5)=\text { moderately acceptable, }(9)=\text { very acceptable }\end{array}$ & $.93^{b}$ & $.79^{\mathrm{a}}$ & $.81^{\mathrm{b}}$ \\
\hline Extension fit & $\begin{array}{l}\text { Please indicate the degree to which the [brand name] brand goes well with [extension product]. } \\
\text { How similar is the image of [extension product] to the image of the [brand name] brand? } \\
\text { Anchors }(1)=\text { does not go well together/not similar at all, }(9)=\text { goes very well together, very similar }\end{array}$ & $.93^{\mathrm{a}}$ & $.88^{\mathrm{a}}$ & $.74^{\mathrm{a}}$ \\
\hline Brand excerpt believability & $\begin{array}{l}\text { How believable is the description about [brand name]'s [extension product]? } \\
\text { How trustworthy is the description about [brand name]'s [extension product]? } \\
\text { Anchors }(1)=\text { not at all believable/trustworthy, }(9) \text { = very believable/trustworthy }\end{array}$ & $.90^{2}$ & $.83^{\mathrm{a}}$ & $.87^{\mathrm{a}}$ \\
\hline
\end{tabular}

a Correlations reported for 2 -item measures.

b Cronbach alphas reported for 3-item measures.

\section{Innovative vs. ordinary benefits}

We pretested extension benefits to validate their characterization as innovative vs. ordinary. Two items (new and useful) indicated innovativeness (Goldenberg et al., 1999; Moreau \& Dahl, 2005; see Table 1). We also used a global measure that asked respondents to rate: "How innovative are the benefits of Lenovo bed sheets?" ( $1=$ "not at all innovative", 9 = "very innovative"). Benefits perceived as high in novelty and low in usefulness or vice versa were not perceived as innovative using this global measure ( $\mathrm{Ms}=3.00$ and 3.50 , respectively; $\mathrm{t}(3)=1.34, p=\mathrm{ns}$ ). The two-item index was strongly correlated with the global judgment of benefit innovativeness ( $r=.93)$. Thus, we combined the three items (benefit novelty, usefulness, innovativeness) to form an overall manipulation check measure of benefit innovativeness (a $=.91)$.

\section{Respondents and procedures}

Three hundred eighteen students participated in Study 1 as part of a regular course requirement. Respondents were randomly assigned to one of the ten conditions outlined in Fig. 1. Respondents first indicated their familiarity with the brand. Next they judged the brand's reputation and breadth. Finally, they rated their perception of the parent brand in 
terms of its functional or symbolic image. All constructs were measured identically to the pretest. Respondents then read a brief paragraph that stated that the focal brand (either Lenovo or Acer) had introduced a new product (portable navigation system or bed sheets). At this point, no product benefit information was presented. We then asked respondents to evaluate how surprised they were to learn of this brand extension.

Next, respondents saw an excerpt, ostensibly from the new product section of a local newspaper that identified the benefits of a proposed new brand extension. To enhance external validity, we used the innovative benefits that had previously been introduced to the marketplace. The web appendix shows sample excerpts for the high reputation/low fit brand with innovative benefits. Respondents in the control condition read no excerpt and hence did not answer the questions that follow.

We asked respondents in the eight experimental conditions to evaluate the brand extension and the parent brand. We then asked respondents to indicate how motivated they were to process the information about the extension provided in the product description. Respondents also rated the perceived innovativeness of the benefits in the extension category and their trust in the parent brand's ability to deliver them. Note that respondents evaluated the extension and the parent brand before they rated their motivation to process benefit information and assess the benefits' innovativeness. This order reduces the possibility that the process-related questions would impact extension and parent brand evaluations.

Next, respondents indicated what associations they linked to the parent brand. These associations were identified in a pretest $(N=51)$. Performance, dependability, and long lasting products were regarded as core associations to both brands $(\mathrm{a}=.88 ;$ MLenovo $=7.28$ and MAcer $=6.35 ; \mathrm{t}(49)=2.11, p<.05)$. In contrast, associations such as comfort, fun, and inspiration were not strongly associated with either brand in the pretest (MLenovo $=2.39$ and $\mathrm{MAcer}=2.13 ;<49)=.88, p$ $=n s)$. A strengthening of parent brand associations and the extent to which novel associations are incorporated into the parent brand schema served as an indicator of positive spillover effects. Acceptance of new low fit extensions served as another indicator of positive spillover effects. Thus, respondents indicated their acceptance of new low fit brand extensions (sunglasses, couches, and compact air purifiers) (see Table 1). These three brand extension categories were based on a pretest $(N=51)$ that revealed that respondents regarded them as low in fit with the parent brand (MLenovo $=2.19$ and MAcer $=2.00 ; \mathrm{t}(49)=.66, p=\mathrm{ns})$.

Respondents then rated the fit between the extension and the parent brand and evaluated excerpt's believability. Finally, they indicated if they had ever owned a Lenovo (Acer) branded product ( $0=$ "no", $1=$ "yes"), whether they currently own a Lenovo (Acer) branded product ( 0 = "no", $1=$ "yes"), and whether they are male (0) or female (1).

\section{Results}

\section{Manipulation checks}

A set of 2 (strong vs. weak brand reputation) x 2 (high vs. low fit) $\times 2$ (innovative vs. ordinary benefits) ANOVAs on the manipulation checks with the Sidak correction for multiple tests revealed that the manipulations were successful (see Table 2). The Sidak correction was applied to all ANOVAs reported in our studies. The strong reputation brand was 
regarded as stronger in reputation than the weak reputation brand (Mstrongreputation $=7.03$ vs. Mweak reputation $=$ 3.39; $F(1,255)=346.41, p<.001)$. High fit brand extensions were regarded as higher in fit than the low fit brand extensions (Mhigh fit $=7.15$ vs. Mlowfit=1.73; $F(1,255)=2019.77, p<.001$ ). Finally, extensions with innovative benefits conditions were regarded as having more innovative benefits than those with the ordinary benefits (Minnovative $=7.23$ vs. Mordinary $=3.22 ; F(1,255)=438.05, p<.001)$. No other effects were observed for these variables.

\section{Confound checks}

A set of $2 \times 2 \times 2$ ANOVAs indicated that the conditions did not differ in ways that might produce potential confounds; there were no differences across the conditions in brand familiarity, perceived brand functional/symbolic expressiveness, brand breadth, excerpt believability, consumers' previous/current brand ownership, or gender (see Table 2).

\section{Effects on brand extension evaluations and positive spillover effects}

\section{Brand extension evaluations}

A 2 (strong vs. weak brand reputation) $\times 2$ (high vs. low fit) $\times 2$ (innovative vs. ordinary benefits) ANOVA on brand extension evaluations revealed main effects of brand reputation

(Mstrong reputation = 5.04 vs. Mweak reputation = 4.02; $\mathrm{F}(1,255)=36.84, p<.001)$, fit (Mhigh fit = 5.21 vs. Mlowfit = 3.85; $F(1,255)=64.99, p<.001)$, and extension benefit innovativeness (Minnovative $=6.19$ vs. Mordinary $=2.87 ; F(1,255)=$ 388.33, $p<.001)$. We observed two-way interactions between brand reputation and fit $(F(1,255)=52.81, p<.001)$, between brand reputation and benefit innovativeness $(F(1,255)=9.80, p<.01)$, and between benefit innovativeness and fit $(F(1,255)=12.87, p<.001)$, and a significant three-way interaction $(F(1,255)=16.00, p<.001)$. Table 2 lists mean scores for each condition.

In support of our theorizing, when brand reputation was strong, extensions with innovative benefits were evaluated more favorably than extensions with ordinary benefits, irrespective of fit. High and low fit extensions were equally liked $($ Mhigh fit $=5.08$ vs. Mlowfit $=4.91 ;<125)=.38, p=n s)$ and extensions with innovative benefits were evaluated more favorably than those with ordinary benefits (Minnovative $=6.97$ vs. Mordinary $=3.12 ;<125)=14.92, p<.001$ ).

We predicted a different set of effects when brand reputation is weak. Here, low fit extensions were evaluated less favorably than high fit extensions (Mlowfit $=2.73$ vs. Mhigh fit $=5.38 ;<126)=7.63, p<.001$ ). The high fit extension with innovative benefits was evaluated more favorably than its low fit counterpart ( $\mathrm{Ms}=7.35$ and 3.48, respectively; $t(63)=$ $12.30, p<.001$ ) and it was liked more than any other extension condition (see Table 2). Thus, the predicted results for brand extension evaluations were fully supported.

\section{Positive spillover effects}

We created a composite measure of positive spillover effects by combining acceptance of novel parent brand associations (comfort, fun, and inspiration), parent brand evaluations, and acceptance of new low fit extensions (sunglasses, couches, and compact air purifiers). Results for this composite measure were replicated when each measure in the composite was examined separately. Details can be obtained from the authors. 
A 2 (strong vs. weak brand reputation) $\times 2$ (high vs. low fit) $\times 2$ (innovative vs. ordinary benefits) ANOVA on composite spillover effects revealed main effects of brand reputation Mstrong reputation 4.47 vs. Mweakreputation 3.10; $F(1,255)$ 209.50, $p<.001)$, fit (Mlowfit $=3.52$ vs. Mhigh fit $=4.05 ; F(1,255)=32.11, p<.001)$, and extension benefit innovativeness (Minnovative $=4.89$ vs. Mordinary $=2.68 ; F(1,255)=544.27, p<.001)$.

Table 2

Study 1: Manipulation checks and hypotheses testing.

\begin{tabular}{|c|c|c|c|c|c|c|c|c|c|c|}
\hline \multirow[t]{2}{*}{ Means } & \multicolumn{5}{|c|}{ Extensions to Lenovo (strong brand reputation) } & \multicolumn{5}{|c|}{ Extensions to Acer (weak brand reputation) } \\
\hline & $\begin{array}{l}\text { High fit/ } \\
\text { innovative } \\
\text { benefits } \\
(\mathrm{N}=31)\end{array}$ & $\begin{array}{l}\text { High fit/ } \\
\text { ordinary } \\
\text { benefits } \\
(\mathrm{N}=32)\end{array}$ & $\begin{array}{l}\text { Low fit/ } \\
\text { innovative } \\
\text { benefits } \\
(\mathrm{N}=31)\end{array}$ & $\begin{array}{l}\text { Low fit/ } \\
\text { ordinary } \\
\text { benefits } \\
(\mathrm{N}=33)\end{array}$ & $\begin{array}{l}\text { Baseline } \\
\text { control } \\
(\mathrm{N}=32)\end{array}$ & $\begin{array}{l}\text { High fit/ } \\
\text { innovative } \\
\text { benefits } \\
(\mathrm{N}=33)\end{array}$ & $\begin{array}{l}\text { High fit/ } \\
\text { ordinary } \\
\text { benefits } \\
(\mathrm{N}=31)\end{array}$ & $\begin{array}{l}\text { Low fit/ } \\
\text { innovative } \\
\text { benefits } \\
(\mathrm{N}=32)\end{array}$ & $\begin{array}{l}\text { Low fit/ } \\
\text { ordinary } \\
\text { benefits } \\
(\mathrm{N}=32)\end{array}$ & $\begin{array}{l}\text { Baseline } \\
\text { control } \\
(\mathrm{N}=31)\end{array}$ \\
\hline \multicolumn{11}{|l|}{ Manipulation checks } \\
\hline Brand reputation & $7.16^{\mathrm{a}}$ & $7.03^{\mathrm{a}}$ & $6.98^{\mathrm{a}}$ & $6.94^{\mathrm{a}}$ & $7.00^{\mathrm{a}}$ & $3.64^{b}$ & $3.73^{\mathrm{b}}$ & $3.44^{b}$ & $3.56^{\mathrm{b}}$ & $3.55^{\mathrm{b}}$ \\
\hline Extension fit & $7.02^{\mathrm{a}}$ & $7.20^{\mathrm{a}}$ & $1.81^{\mathrm{b}}$ & $1.62^{\mathrm{b}}$ & na & $7.00^{\mathrm{a}}$ & $7.39^{\mathrm{a}}$ & $1.69^{\mathrm{b}}$ & $1.80^{\mathrm{b}}$ & na \\
\hline \multicolumn{11}{|l|}{ Confounds } \\
\hline Brand familiarity & $6.81^{\mathrm{a}}$ & $7.00^{\circ}$ & $6.87^{2}$ & $6.61^{\mathrm{a}}$ & $6.78^{\mathrm{a}}$ & $6.82^{2}$ & $6.52^{\mathrm{a}}$ & $6.44^{\mathrm{a}}$ & $6.50^{\mathrm{a}}$ & $6.55^{\mathrm{a}}$ \\
\hline Functional/symbolic brand & $3.29^{\mathrm{a}}$ & $3.14^{3}$ & $3.21^{\mathrm{a}}$ & $3.02^{\mathrm{a}}$ & $3.30^{\mathrm{a}}$ & $2.98^{a}$ & $2.69^{\mathrm{a}}$ & $2.95^{\mathrm{a}}$ & $2.80^{\mathrm{a}}$ & $2.92^{\mathrm{a}}$ \\
\hline Brand breadth & $2.34^{\mathrm{a}}$ & $2.34^{4}$ & $2.31^{\mathrm{A}}$ & $2.58^{\mathrm{a}}$ & $2.53^{\mathrm{a}}$ & $2.41^{\mathrm{a}}$ & $2.74^{\mathrm{a}}$ & $2.32^{2}$ & $2.42^{\mathrm{a}}$ & $2.55^{\mathrm{a}}$ \\
\hline Brand excerpt believability & $7.39^{\mathrm{a}}$ & $7.83^{a}$ & $7.40^{\mathrm{a}}$ & $7.35^{\mathrm{a}}$ & $\mathrm{Na}$ & $7.21^{\mathrm{a}}$ & $7.48^{\mathrm{a}}$ & $7.23^{a}$ & $7.20^{\mathrm{a}}$ & na \\
\hline Brand ownership & $.23^{\mathrm{a}}$ & $.19^{a}$ & $.19^{\mathrm{a}}$ & $.12^{\mathrm{a}}$ & $.16^{\mathrm{a}}$ & $.12^{\mathrm{a}}$ & $.16^{\mathrm{a}}$ & .16 & $.16^{\mathrm{a}}$ & $.13^{\mathrm{a}}$ \\
\hline \multicolumn{11}{|l|}{ Dependent variables } \\
\hline Composite spillover effects & $5.21^{\mathrm{b}}$ & $3.30^{\circ}$ & $6.99^{\mathrm{a}}$ & $2.39^{d}$ & $3.35^{\circ}$ & $4.80^{\mathrm{b}}$ & $2.91^{\text {od }}$ & $2.58^{\circ}$ & $2.11^{\mathrm{f}}$ & $2.69^{\mathrm{de}}$ \\
\hline Novel parent brand associations & $4.11^{\mathrm{b}}$ & $2.38^{\circ}$ & $6.15^{\mathrm{a}}$ & $2.18^{\circ}$ & $2.52^{\circ}$ & $3.68^{\mathrm{b}}$ & $2.41^{\circ}$ & $2.23^{\circ}$ & $2.17^{\circ}$ & $2.20^{\circ}$ \\
\hline Parent brand evaluations & $7.18^{\mathrm{b}}$ & $4.67^{\mathrm{d}}$ & $8.03^{\mathrm{a}}$ & $2.68^{f}$ & $5.00^{\mathrm{d}}$ & $6.24^{\mathrm{c}}$ & $3.48^{\circ}$ & $2.94^{\mathrm{ff}}$ & $2.08^{\mathrm{g}}$ & $3.42^{\mathrm{e}}$ \\
\hline Acceptance of funure low fit extensions & $4.33^{\mathrm{b}}$ & $2.85^{\circ}$ & $6.77^{\mathrm{a}}$ & $2.31^{\text {od }}$ & $2.54^{\mathrm{od}}$ & $4.46^{\mathrm{b}}$ & $2.85^{\circ}$ & $2.56^{\mathrm{od}}$ & $2.09^{\mathrm{d}}$ & $2.44^{\text {od }}$ \\
\hline Core parent brand associations & $7.35^{\mathrm{a}}$ & $7.09^{\mathrm{a}}$ & $7.43^{\mathrm{a}}$ & $7.18^{\mathrm{a}}$ & $7.22^{\mathrm{a}}$ & $6.27^{\mathrm{b}}$ & $6.32^{\mathrm{b}}$ & $6.52^{\mathrm{b}}$ & $5.09^{\circ}$ & $6.37^{\mathrm{b}}$ \\
\hline \multicolumn{11}{|c|}{ Variables relevant to the underlying logic of hypotheses } \\
\hline Trust in extension benefits & $6.11^{\mathrm{a}}$ & $6.05^{\mathrm{a}}$ & $6.09^{\mathrm{a}}$ & $6.23^{\mathrm{a}}$ & na & $3.86^{\mathrm{b}}$ & $3.40^{\mathrm{b}}$ & $2.11^{\circ}$ & $2.48^{\circ}$ & na \\
\hline Extension surprise & $2.42^{\mathrm{b}}$ & $2.77^{b}$ & $7.33^{\mathrm{a}}$ & $7.20^{\mathrm{a}}$ & na & $2.68^{b}$ & $2.75^{\mathrm{b}}$ & $7.15^{\mathrm{a}}$ & $7.13^{\mathrm{a}}$ & na \\
\hline Motivation to process & $4.72^{\mathrm{b}}$ & $4.39^{b}$ & $6.70^{\mathrm{a}}$ & $5.95^{\mathrm{a}}$ & na & $4.73^{\mathrm{b}}$ & $4.83^{\mathrm{b}}$ & $6.44^{\mathrm{a}}$ & $6.46^{\mathrm{a}}$ & na \\
\hline
\end{tabular}

Means with different superscripts are significantly different, $p<.05$; Bold-faced means show successful manipulation checks or support for our hypotheses.

The results also revealed two-way interactions between brand reputation and fit $(F(1,255)=105.36, p<.001)$, between brand reputation and extension benefit innovativeness $(F(1,255)=120.15, p<.001)$, and between extension fit and benefit innovativeness $(F(1,255)=11.24, p<.001)$. Most significantly, the results revealed the predicted three-way interaction between parent brand reputation, extension fit, and benefit innovativeness $(F(1,255)=117.26, p<.001)$. Fig. 2 depicts this interaction.

Fig. 2A illustrates the results for the strong reputation brand. As shown, positive spillover effects were greatest when innovative benefits were offered by a low (vs. high) fit extension (e.g., Mlowfit-innovative $=6.99$ vs. Mhigh fit-innovative $=5.21 ; \mathrm{t}(60)=8.21, p<.001)$. Fig. $2 \mathrm{~B}$ illustrates the results for the weak reputation brand. As shown, positive spillover effects were strongest when the parent brand extended to a high (vs. low) fit product with innovative benefits (e.g., Mhigh fitinnovative 4.80 vs. Mlowfit-innovative $2.58 ; \mathrm{t}(63) 11.19, p<.001)$. Contrast analyses that examine the patterns of these interactions are detailed in Table 2. Importantly, and as Table 2 shows, core associations (performance, dependability, and long lasting products) of the parent brands were not diluted by the introduction of low fit extension with innovative benefits (Lenovo: Mcontrol $=7.22$ vs. Mlow fit-innovative $=7.43 ; \mathrm{t}(61) .69, p=\mathrm{ns} ;$ Acer: Mcontrol $=6.37$ vs. Mlow fit- 
innovative $=6.52 ; \mathrm{t}(61)=.30, p=\mathrm{ns})$. Thus, the predicted positive spillover effects were observed.

\section{Evidence for proposed processes}

\section{Process measures}

A set of 2 (strong vs. weak brand reputation) x 2 (high vs. low fit) $\times 2$ (innovative vs. ordinary benefits) ANOVAs was conducted on the process variables underlying our predictions. ANOVAs on respondents' surprise about the brand extension and motivation to process brand extension-related information revealed a main effect of fit. As predicted, respondents were more surprised by the brand extension (Mlow fit $=7.20$ vs. Mhigh fit $=2.66 ; F(1,255)=1149.52, p<$ .001 ) and were more motivated to process information about its benefits when fit was low vs. high (Mlow fit $=6.39$ vs. Mhigh fit $=4.67 ; F(1,255)=70.03, p<.001 ;$ Table 2$)$. No other effects were observed.

Also as predicted, respondents had stronger trust in the parent's brand ability to deliver on promised extension benefits when brand reputation was strong vs. weak (Mstrong reputation = 6.12 vs. Mweak reputation $=p<.001 ;$ Table 2). Further, results show that for the strong reputation brand, there is no difference in trust in delivering the promised extension benefits between the high fit $(M=6.08)$ and low fit conditions $(M=6.16 ; t(125)=.25, p=n s)$. Supporting our theorizing, the results showed significantly stronger trust in the weak reputation brand's ability to deliver the promised extension benefits in the high vs. low fit condition (Mhigh fit $=3.64 \mathrm{vs}$. Mlow fit $=2.30 ; t(126)=8.62, p<.001$ ).

A)

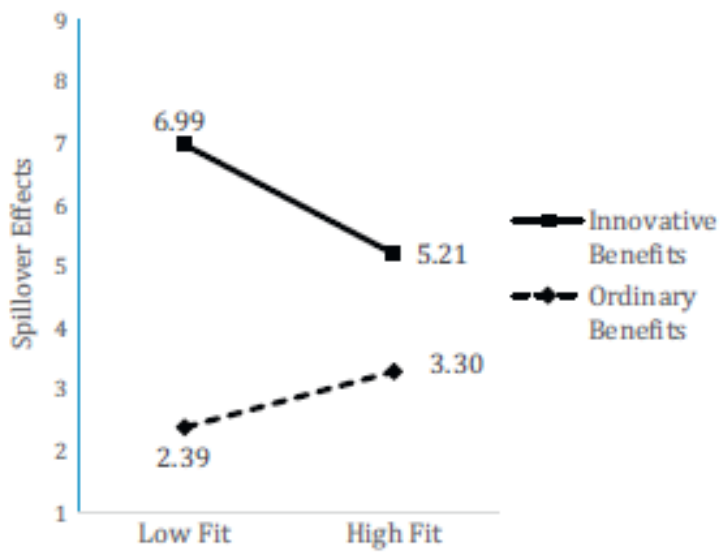

B)

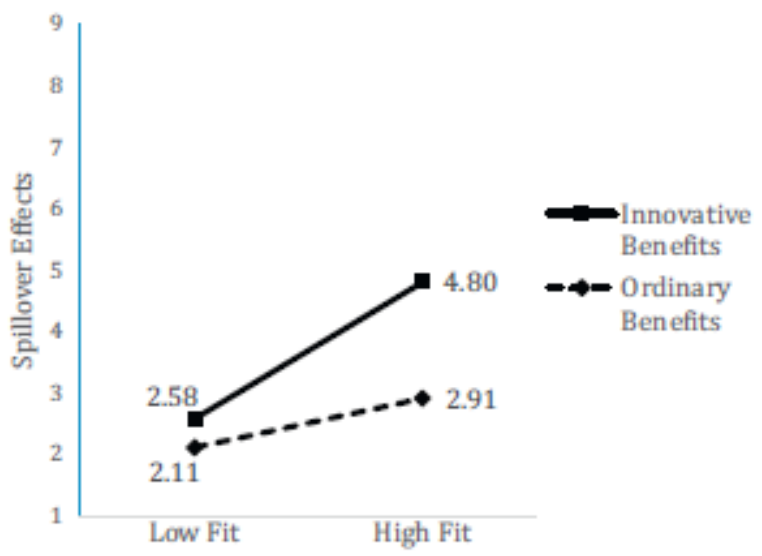

Fig. 2. A. Study 1: Strong reputation brand and spillover effects. B. Study 1: Weak reputation brand and spillover effects. 


\section{Mediational analysis for the strong reputation brand}

To further examine the mechanism underlying our results, we followed Hayes' (2012) recommended bootstrapping technique and examined the mediating roles of respondents' motivation to process the information about extension benefits and their trust in the parent brand's ability to deliver promised extension benefits on the relationship between extension fit and spillover effects on the parent brand.

For the strong reputation brand with innovative extension benefits, low fit enhances motivation to process the extension's innovative benefits $(B=-1.98, \mathrm{SE}=.22, t=-9.08, p<.001,95 \%$ bootstrap confidence interval $(\mathrm{Cl})-2.42$ to 1.54), which in turn strengthens positive spillover effects on the parent brand $(\mathrm{B}=.91, \mathrm{SE}=.06, t=14.45, p<.001,95 \% \mathrm{Cl}$ .78 to 1.03). Detailed results of the total, direct, and indirect effects (via motivation to process) of fit on the reputable brand's spillover effects are reported in Table 3A.

Also as expected, trust in the brand's ability to deliver promised extension benefits played no mediating role in the relationship between fit and positive spillover effects for the strong reputation brand. Specifically, fit had a strong direct effect on parent brand spillover effects $(B=-1.78, S E=.22, t=-8.05, p<.001,95 \% \mathrm{Cl}-2.22$ to -1.34$)$. Fit, however, did not affect trust ( $\mathrm{B}=.02, \mathrm{SE}=.45, t=.04, p=\mathrm{ns}, 95 \% \mathrm{Cl}-.91$ to .88$)$, which in turn did not influence the strong parent brand's spillover effects $(\mathrm{B}=-.07, \mathrm{SE}=.06, t=-1.22, p=\mathrm{ns}, 95 \% \mathrm{Cl}-.19$ to .05$)$.

\section{Mediational analysis for the weak reputation brand}

For the weak reputation brand with innovative extension benefits, the results revealed that trust mediates the influence of fit on the positive spillover effects. Specifically, fit strengthens trust in the weak reputation parent brand's ability to reliably deliver on promoted extension benefits $(B=1.75, \mathrm{SE}=.20, t=8.86, p<.001,95 \% \mathrm{Cl} 1.36$ to 2.15 ), which in turn creates positive parent brand spillover effects ( $B=.73, \mathrm{SE}=.08, t=8.93, p<.001,95 \% \mathrm{Cl} .57$ to .89 ). We also observed a direct effect of fit on spillover effects. Detailed results of the total, direct, and indirect effects (via trust) of fit on the weak reputation brand's spillover effects are reported in Table 3B.

In contrast to the strong reputation brand, and in line with our theorizing, motivation to process extension benefits did not mediate the influence of fit on positive spillover effects for the weak reputation brand. That is, low fit had a direct effect on spillover effects ( $\mathrm{B}=2.20, \mathrm{SE}=.24, t=9.31, p<.001,95 \% \mathrm{Cl} 1.73$ to 2.67$)$ and enhanced motivation to process the benefits of the extension ( $\mathrm{B}=-1.71, \mathrm{SE}=.44, t=-3.91, p<.001,95 \% \mathrm{Cl}-2.59$ to .84 ), but motivation to process did not influence the weak reputation brand's spillover effects $(\mathrm{B}=-.01, \mathrm{SE}=.07, t=-.19, p=\mathrm{ns}, 95 \% \mathrm{Cl}-.15$ to .12$)$.

\section{Discussion}

Study 1 supported $\mathrm{H} 1-\mathrm{H} 4$. For strong reputation brands, the dual outcomes of positive brand extension evaluations and positive spillover effects are maximized when the brand extension is low in fit and offers innovative benefits (H1) because low fit motivates consumers to process innovative brand extension information more deeply (H2). Importantly, novel parent brand associations created by the low fit extension with innovative benefits do not dilute the strong reputation brand's core brand associations. For weak reputation brands, favorable brand extension evaluations and 
spillover effects are maximized when the brand extension is high in fit and offers innovative benefits (H3) because high fit strengthens consumers' trust in the weak brand's ability to deliver innovative benefits ( $\mathrm{H} 4)$.

Study 2 aimed to replicate $\mathrm{H} 1-\mathrm{H} 4$ using different brands with different images (symbolic vs. functional) in a different category (fashion) and using different extension benefits. Study 2 also asked hypotheses-related questions in a different order, so as to rule out measurement order as a factor that might explain Study 1's results.

Table 3

Study 1: Mediation analyses.

\begin{tabular}{|c|c|c|c|c|c|c|}
\hline Mediator variable model (predicting motivation to process) & $\mathrm{R}^{2}$ & $\mathrm{~F}(1,60)$ & $\mathrm{B}(\mathrm{SE})$ & $\mathrm{T}$ & LLCI & ULCI \\
\hline Fit & .59 & $82.38^{* * *}$ & $-1.98(.22)$ & $-9.08 * * *$ & -2.42 & -1.54 \\
\hline Dependent variable model (predicting spillover effects) & $\mathrm{R}^{2}$ & $F(2,59)$ & $\mathrm{B}(\mathrm{SE})$ & $T$ & LLCI & ULCI \\
\hline Motivation to process & .91 & $283.88^{* * *}$ & $.91(.06)$ & $14.45^{* * *}$ & .78 & 1.03 \\
\hline Fit & & & $.01(.17)$ & .07 & -.34 & .32 \\
\hline Total effect of fit on spillover effects & $\mathrm{R}^{2}$ & $F(1,60)$ & $\mathrm{B}(\mathrm{SE})$ & $T$ & LLCI & ULCI \\
\hline Fit & .53 & $65.22^{* * *}$ & $-1.78(.22)$ & $-8.08 * * *$ & -2.22 & -1.34 \\
\hline \multicolumn{7}{|l|}{ Direct effect of fit on spillover effects } \\
\hline Fit & & & $.01(.17)$ & .07 & -.34 & .32 \\
\hline \multicolumn{7}{|l|}{ Indirect effect of fit on spillover effects } \\
\hline Motivation to process & & & $-1.79(.23)$ & & -2.26 & -1.37 \\
\hline \multicolumn{7}{|l|}{ (B): Weak reputation brand (Acer)/innovative extension benefits } \\
\hline Mediator variable model (predicting brand thust with extension benefits) & $\mathrm{R}^{2}$ & $F(1,63)$ & $\mathrm{B}(\mathrm{SE})$ & $T$ & LLCI & ULCI \\
\hline Fit & .56 & $78.42^{* * *}$ & $1.75(.20)$ & $8.86^{* * *}$ & 1.36 & 2.15 \\
\hline Dependent variable model (predicting spillover effects) & $\mathrm{R}^{2}$ & $F(2,62)$ & $\mathrm{B}(\mathrm{SE})$ & $T$ & LLCI & ULCI \\
\hline Trust in extension benefits & .84 & $214.45^{* * *}$ & $.73(.08)$ & $8.93^{* * *}$ & .57 & .89 \\
\hline Fit & & & $.94(.22)$ & $4.19^{* * *}$ & .49 & 1.39 \\
\hline Total effect of fit on spillover effects & $\mathrm{R}^{2}$ & $F(1,63)$ & $\mathrm{B}$ (SE) & $t$ & LLCI & ULCI \\
\hline Fit & .67 & $123.28^{* * *}$ & $2.22(.20)$ & $11.10^{* * *}$ & 1.82 & 2.62 \\
\hline \multicolumn{7}{|l|}{ Direct effect of fit on spillover effects } \\
\hline Fit & & & $.94(.22)$ & $4.19 * * *$ & .49 & 1.39 \\
\hline \multicolumn{7}{|l|}{ Indirect effect of fit on spillover effects } \\
\hline Trust in extension benefits & & & $1.28(.20)$ & & .92 & 1.68 \\
\hline
\end{tabular}

\section{Study 2}

\section{Method}

Study 2 used a 2 (strong vs. weak brand reputation) x 2 (high vs. low fit) $\times 2$ (innovative vs. ordinary benefits) betweensubjects experimental design with two baseline control conditions for each brand (see Fig. 3). The two baseline control conditions queried respondents about the parent brand but did not expose them to information about the brand extension or ask questions pertinent to brand extension judgments. Unless otherwise indicated, all items in Study 2 and its pretest were measured identically to Study 1.

\section{Pretests}

Two fashion apparel brands, Armani and Burberry, were selected as focal parent brands, based on a pretest $(\mathrm{N}=42)$ 
that demonstrated a difference in their reputation levels among UK respondents (where Study 2 was conducted). In the UK, Burberry is not regarded as a strong reputation brand among the young respondents who participated in our study, since an anti-social youth subculture whose members are referred to as "chavs" has tarnished its image. Detailed pretest results are listed in the web appendix.

Desk clocks and bed sheets were selected as brand extension categories. A pretest $(N=42)$ revealed that desk clocks were perceived as low in fit with Armani and Burberry, whereas bed sheets were regarded as high in fit. Innovative and ordinary benefits were also selected, based on a pretest $(N=50)$ that validated their status as innovative or ordinary.

\section{Respondents and procedures}

Two hundred eighty nine undergraduate students took part in Study 2 as part of a regular course. Respondents were randomly assigned to one of the 10 conditions shown in Fig. 3. Table 1 shows the reliabilities of each measure used in Study 2.

First, respondents were asked to indicate their familiarity with the parent brand (either Armani or Burberry) and their perception of the brand's reputation. They then read a brief paragraph that stated that the parent brand had introduced a new product to the market (either bed sheets or a desk clock). Respondents were asked to evaluate the extent to which they felt surprised by this brand extension. At this point, no product benefit information was presented.

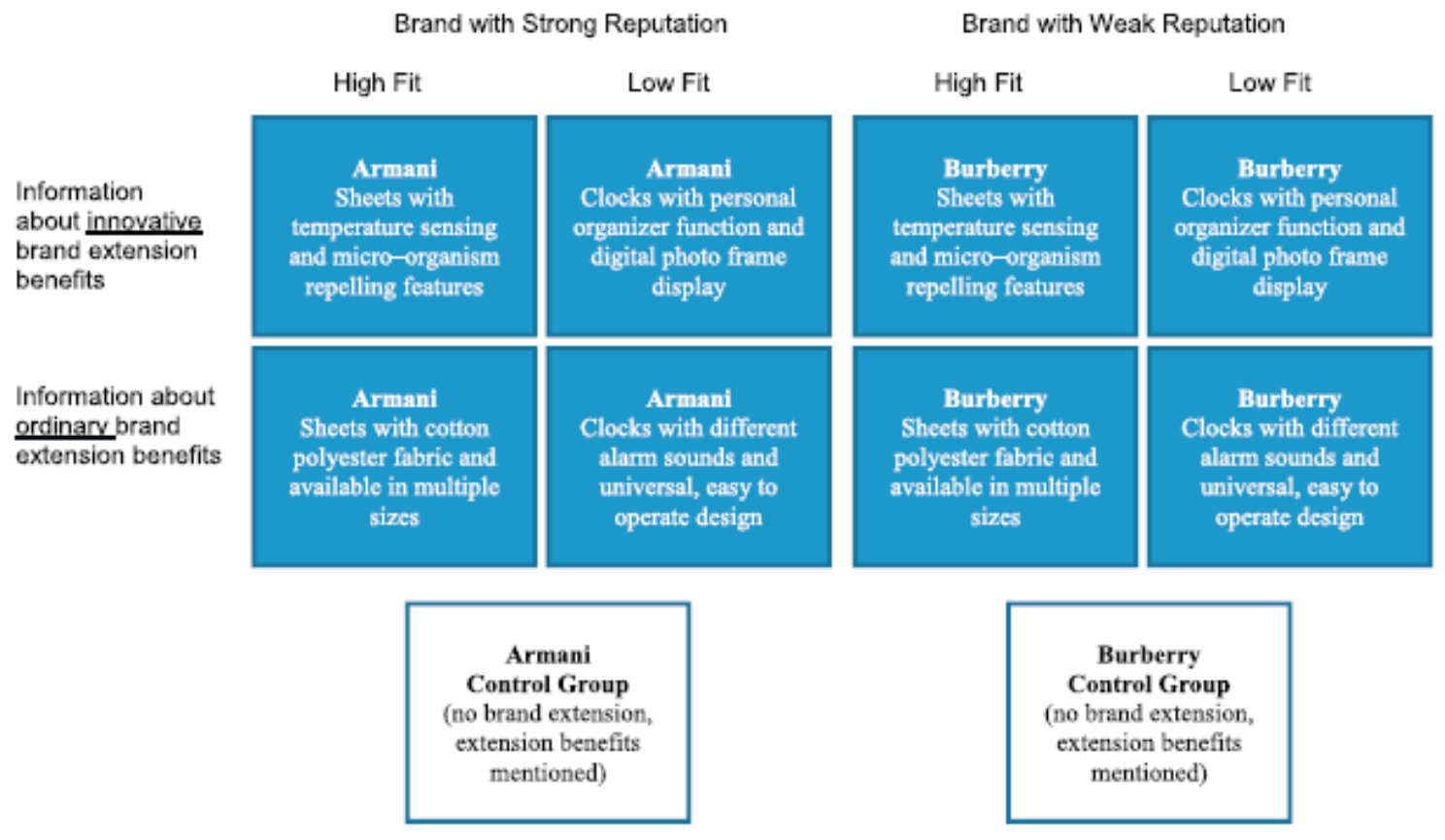

Fig. 3. Study 2: Experimental conditions.

Respondents then read an excerpt detailing product benefits ostensibly from the new product section of a parent magazine. The web appendix shows a sample excerpt for the high reputation/low fit brand with innovative benefits. Respondents were asked to indicate how motivated they were to process the information presented while reading the product description. Control respondents read no excerpt and hence did not answer questions related to the excerpt. 
Respondents then evaluated the brand extension and the parent brand. Next they indicated their trust in the parent brand's ability to deliver promised extension benefits. They then indicated the extent to which associations that had been identified in a pretest $(\mathrm{N}=50)$ as core (fun and stylish) or novel to each parent brand's schema (i.e., relaxation and greater control of daily life) were linked with the parent brand. Respondents also indicated their acceptance of two new extensions that were identified in a pretest $(\mathrm{N}=50)$ as low in fit with the Armani and Burberry brands (sun protection lotion and bathroom scales). We also tested acceptance of two future extensions identified in a pretest ( $N=50)$ as high in fit with the parent brands. Overall, the results for acceptance of new high fit extensions were the same as for the low fit extensions and are not addressed further. Finally, respondents assessed the fit between the brand extension and the parent brand and rated the excerpt's believability.

\section{Results}

\section{Manipulation checks}

A set of 2 (strong vs. weak brand reputation) $\times 2$ (high vs. low fit) $\times 2$ (innovative vs. ordinary benefits) ANOVAs on the manipulation checks revealed that the manipulations were successful (Table 4). The manipulation check for brand reputation revealed the expected main effect of brand reputation (Mstrong reputation= 7.2 vs. Mweak reputation=3.32; $F(1,233)=212.55, p<.001)$. The manipulation check for fit also revealed the expected main effect of fit (Mhigh flt $=6.75$ vs. Mlow fit $=1.48 ; F(1,233)=992.72, p<.001)$. Finally, the manipulation check for benefit innovativeness showed a main effect of benefit innovativeness (Minnovative $=7.89$ vs. Mordinary $=3.54 ; F(1,233)=702.24, p<.001$ ). No other effects were observed.

\section{Confound checks}

As illustrated in Table 4, a set of $2 \times 2 \times 2$ ANOVAs on variables that might produce potential confounds showed that there were no differences across the conditions in brand familiarity and brand excerpt believability.

Effects on brand extension evaluations and positive spillover effects

\section{Brand extension evaluations}

A $2 \times 2 \times 2$ ANOVA on the measure of brand extension evaluations revealed main effects of brand reputation (Mstrong reputation 5.57 vs. Mweakreputation 4.98; $F(1,233)=8.93, p<.01$ ), fit (Mhigh fit = 5.97 vs. $M W$ fit = 4.58; $F(1$, $233)=51.18, p<.001$ ), and extension benefit innovativeness (Minnovative=6.89 vs. Mordinary=3.66; $F(1,233)=273.91$, $p<.001)$. The results also revealed two-way interactions between brand reputation and fit $(\mathrm{F}(1,233)=26.01, p<.001)$ and between brand reputation and extension benefit innovativeness $(F(1,233)=14.75, p<.001)$. The three-way interaction between brand reputation, benefit innovativeness, and fit was not significant $(\mathrm{F}(1,233)=.33, p=\mathrm{ns})$. 


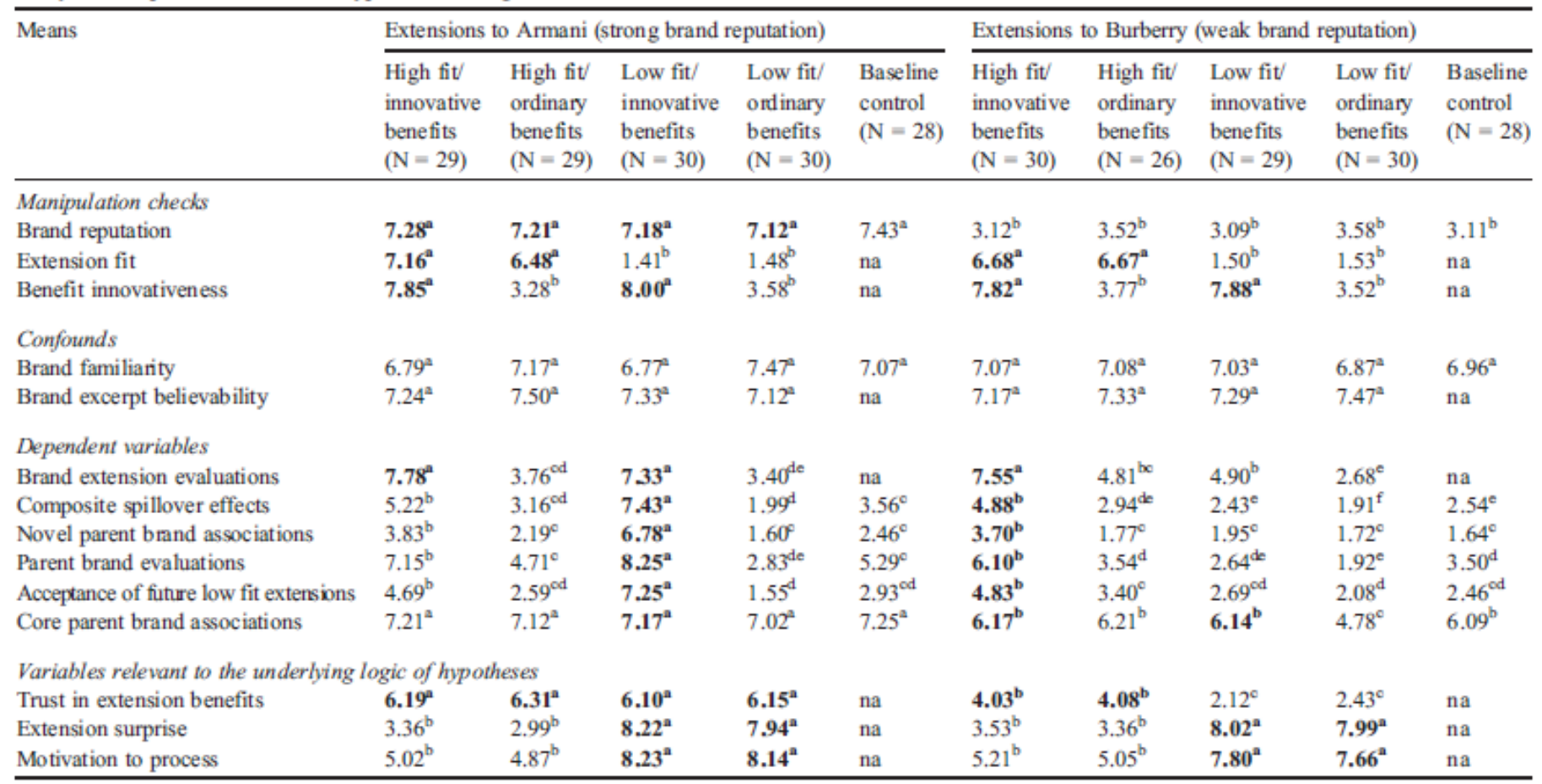

Means with different superscripts are significantly different, $p<.05$; Bold-faced means show successful manipulation checks or support for our hypotheses.

Consistent with our theorizing, and replicating Study 1, when brand reputation was strong, extensions with innovative (vs. ordinary) benefits were evaluated more favorably ( $\mathrm{Ms}=7.55$ and 3.58; $\mathrm{t}(116)=13.23, p<.001$ ), and the high and low fit innovative extensions were equally liked (Ms $=5.77$ and $5.37 ; \mathrm{t}(116)=.84, p=\mathrm{ns}$; Table 4). When brand reputation was weak, high fit extensions were evaluated more favorably than low fit extensions (Mhigh fit = 6.28 vs. Mlow fit = 3.77; $t(113)=7.42, p<.001)$. Specifically, the high fit extension with innovative benefits was evaluated more favorably than its low fit counterpart (Mhigh fit $=7.55$ vs. Mlow fit $=4.90 ; \mathrm{t}(57)=7.51, p<.001$ ), and it was liked more than extensions in any other condition.

\section{Positive spillover effects}

As in Study 1, we combined (a) acceptance of novel parent brand associations (relaxation and greater control of daily life), (b) parent brand evaluations, and (c) acceptance of new low fit extensions (sun protection lotion and bathroom scales) into a composite measure of positive spillover effects $(a=.81)$. Results for the composite measure were replicated when each measure was examined separately. Details can be obtained from the authors.

A $2 \times 2 \times 2$ ANOVA on positive spillover effects revealed main effects of brand reputation (Mstrong reputation $=4.45$ vs. Mweak reputation $=3.03 ; F(1,233)=186.68, p<.001)$, fit $($ Mlow fit $=3.44$ vs. Mhigh fit $=4.04 ; F(1,233)=33.53, p<$ .001 ), and extension benefit innovativeness (Minnovative $=4.99$ vs. Mordinary $=2.49 ; F(1,233)=574.48, p<.001$ ). The results also revealed two-way interactions between brand reputation and fit $(F(1,233)=115.94, p<.001)$, between brand reputation and extension benefit innovativeness $(F(1,233)=144.07, p<.001)$, and between extension fit and benefit innovativeness $(F(1,233)=21.13, p<.001)$. The predicted threeway interaction $(F(1,233)=133.97, p<.001)$ was also observed. Fig. 4 decomposes this interaction for strong and weak reputation brands, respectively. The results replicate 
Study 1.

As predicted and shown in Fig. 4A, when brand reputation was strong, positive spillover effects were strongest when the brand used a low (vs. high) fit extension with innovative benefits (e.g. Mlow fit-innovative $=7.43$ vs. Mhigh fitinnovative $=5.22 ; \mathrm{t}(57)=11.92, p<.001)$. In contrast, Fig. 4B shows that when brand reputation was weak, positive spillover effects were greatest when the brand used a high (vs. low) fit extension and offered innovative benefits (e.g., Mhigh fit-innovative $=4.88$ vs. Mlow fit-innovative $=2.43 ; \mathrm{t}(57)=11.17, p<.001)$. Contrast analyses that examine the detailed patterns of these interactions are shown in Table 4. Also replicating Study 1, core associations (fun and stylish) of the parent brands were not diluted by the low fit extension with innovative benefits (Armani: Mcontrol I-25 vs. Mlow fit-innovative 7.17; $\mathrm{t}(56)=.19, p \mathrm{~ns}$; Burberry: Mcontrol= 6.09 vs. Mlow fit-innovative= 6.14; $\mathrm{t}(55)=.10, p=\mathrm{ns}$; Table 4).

\section{Evidence for proposed processes Process measures}

A set of $2 \times 2 \times 2$ ANOVAs on surprise about the brand extension and motivation to process brand extension-related information found the predicted main effect of fit; respondents were more surprised by the low fit brand extension (Mlow fit $=8.05$ vs. Mhigh fit $=3.31 ; F(1,233)=830.20, p<.001)$ and were more motivated to process information about its benefits when fit was low vs. high $\left(\mathrm{M}_{\text {low fit }}=7.96\right.$ vs. $\mathrm{M}_{\text {high fit }}=5.04 ; F(1,233)=332.87, p<.001 ;$ Table 4). Also as predicted, respondents had greater trust in the parent brand's ability to deliver on innovative extension benefits when brand reputation was strong vs. weak (Mstrong reputation = 6.19 vs. Mweak 3.17; $F(1,233)=309.17, p<.001 ;$ Table 4). Consumers had high trust in the strong reputation brand's ability to deliver on promised brand benefits, regardless of whether it extended to a high fit $(M=6.25)$ or a low fit product category $(M=6.13 ; t(116)=.51, p=n s)$. Also as expected, for the weak reputation brand, consumers had significantly stronger trust in the brand's ability to deliver the promised extension benefits when the brand extended to a high fit $(M=3.96)$ vs. a low fit category $(M=2.36 ; t(113)=5.39, p<.05)$.

\section{Mediation analyses for the strong reputation brand}

We replicate the mediation findings in Study 1 using Hayes' (2012) bootstrapping technique. For the strong reputation brand, motivation to process brand information mediates the influence of fit on positive spillover effects (Table 5A). Specifically, when the strong reputation brand offered innovative extension benefits, low fit enhanced motivation to process extension benefit information $(B=-3.20, \mathrm{SE}=.16, t=-19.69, p<.001,95 \%$ bootstrap confidence interval (CI) 3.52 to -2.87 ), which in turn induced more positive spillover effects $(\mathrm{B}=.67, \mathrm{SE}=.13, t=5.23, p<.001,95 \% \mathrm{Cl} .42$ to .93 ). Detailed results of the total, direct, and indirect effects (via motivation to process) of fit on spillover effects for the strong reputation brand are reported in Table 5A.

In contrast, and replicating Study 1, trust in the brand's ability to deliver promised extension benefits did not mediate the influence of fit on spillover effects for the strong reputation brand. Specifically, fit had a strong direct effect on positive spillover effects $(B=-2.21, \mathrm{SE}=.19, t=-11.61, p<.001,95 \% \mathrm{Cl}-2.59$ to -1.83$)$, but it did not affect trust $(\mathrm{B}=.09, \mathrm{SE}=.36$, $t=.25, p=\mathrm{ns}, 95 \% \mathrm{Cl}-.63$ to .81$)$, nor did trust influence the strong parent brand's spillover effects $(\mathrm{B}=.05, \mathrm{SE}=.09, t=$ $.58, p=\mathrm{ns}, 95 \% \mathrm{Cl}-.13$ to .23$)$. 


\section{Mediation analyses for the weak reputation brand}

Replicating Study 1, when brand reputation was weak and benefits were innovative, high fit reliably strengthened trust in the parent brand's ability to deliver promised extension benefits $(\mathrm{B}=1.90$, $\mathrm{SE}=.22, t=8.75, p<.001,95 \% \mathrm{Cl} 1.46$ to 2.33). In turn, trust positively affected parent brand spillover effects $(B=.57, \mathrm{SE}=.11, t=5.23, p<.001,95 \% \mathrm{Cl} .35$ to .79$)$. Table 5B shows the detailed results of the total, direct, and indirect effects (via trust) of fit on the weak reputation brand's spillover effects.

Finally, and as predicted, for the weak reputation brand, motivation to process extension benefits did not mediate the influence of fit on spillover effects. Consistent with Study 1, low fit had a direct effect on the spillover effects ( $B=2.63, S E$ $=.29, t=9.05, p<.001,95 \% \mathrm{Cl} 2.05$ to 3.21$)$ and enhanced motivation to process ( $\mathrm{B}=-2.59, \mathrm{SE}=.36, t=-7.20, p<.001$, $95 \% \mathrm{Cl}-3.32$ to -1.87$)$, but motivation to process did not influence the weak reputation brand's spillover effects $(B=.07$, $\mathrm{SE}=.08, t=.85, p=\mathrm{ns}, 95 \% \mathrm{Cl}-.15$ to .12$)$.

\section{Discussion}

The results of Study 2 fully support $\mathrm{H} 1-\mathrm{H} 4$ and replicate Study 1, here for symbolic brands. When brand reputation is strong, the dual effects of positive brand extension evaluations and positive spillover effects on the parent brand are maximized when the brand offers a low fit extension with innovative benefits ( $\mathrm{H} 1$ ) because low fit motivates consumers to process innovative brand extension information more deeply $(\mathrm{H} 2)$. In contrast, a weak reputation brand's extensions are evaluated more favorably and positive spillover effects are greatest when a high fit extension offers innovative benefits (H3) because high fit strengthens consumers' trust in the weak brand's ability to deliver on promised innovative benefits $(\mathrm{H} 4)$.

We further conducted Study 3 with four goals in mind. First, we reversed the low vs. high fit extension product categories of Study 2 to rule out the possibility that the previously observed results were driven by the inherent appeal of the benefits offered in the low fit product category. Second, we adopted a more conservative test of Studies 1 and 2 by using delayed measures of the dependent variables. This change enhances the study's ecological validity by showing that the positive spillover effects found in Studies 1 and 2 are observed even after a one-week delay. Third, we added price information to the extension products to further increase the study's ecological validity. Fourth, we tested the effects using a different pair of brands, this time experiential in nature, to test the robustness of the findings of Studies 1 and 2. 
Study 2: Mediation analyses.

\begin{tabular}{|c|c|c|c|c|c|c|}
\hline \multicolumn{7}{|l|}{ (A): Strong reputation brand (Armani)/innovative extension benefits } \\
\hline Mediator variable model (predicting motivation to process) & $\mathrm{R}^{2}$ & $\mathrm{~F}(1,57)$ & $\mathrm{B}(\mathrm{SE})$ & $\mathrm{T}$ & LLCI & $\overline{\mathrm{ULCI}}$ \\
\hline Fit & .88 & $387.71^{* * *}$ & $-3.20(.16)$ & $-19.69 * * *$ & -3.52 & -2.87 \\
\hline Dependent variable model (predicting spillover effects) & $\mathrm{R}^{2}$ & $F(2,56)$ & $\mathrm{B}(\mathrm{SE})$ & $T$ & LLCI & ULCI \\
\hline Motivation to process & .81 & $103.19^{* * *}$ & $.67(.13)$ & $5.23 * * *$ & .42 & .93 \\
\hline Fit & & & $-.05(.36)$ & -.14 & -.77 & .67 \\
\hline Total effect of fit on spillover effects & $\mathbf{R}^{2}$ & $F(1,57)$ & $\mathrm{B}(\mathrm{SE})$ & $T$ & LLCI & ULCI \\
\hline Fit & .71 & $137.64^{* * *}$ & $-2.20(.19)$ & $-11.73^{* * *}$ & -2.58 & -1.83 \\
\hline \multicolumn{7}{|l|}{ Direct effect of fit on spillover effects } \\
\hline Fit & & & $-.05(.36)$ & -.14 & -.77 & .67 \\
\hline \multicolumn{7}{|l|}{ Indirect effect of fit on spillover effects } \\
\hline Motivation to process & & & $-2.15(.37)$ & & -2.79 & -1.32 \\
\hline \multicolumn{7}{|l|}{ (B): Weak reputation brand (Burberry)/innovative extension benefits } \\
\hline Mediator variable model (predicting brand trust with extension benefits) & $\mathrm{R}^{2}$ & $F(1,57)$ & $\mathrm{B}(\mathrm{SE})$ & $T$ & LLCI & ULCI \\
\hline Fit & .58 & $76.60^{* * *}$ & $1.90(.22)$ & $8.75^{* * *}$ & 1.46 & 2.33 \\
\hline Dependent variable model (predicting spillover effects) & $\mathbf{R}^{2}$ & $F(2,56)$ & $\mathrm{B}(\mathrm{SE})$ & $T$ & LLCI & ULCI \\
\hline Trust in extension benefits & .78 & $127.77^{* * *}$ & $.57(.11)$ & $5.23 * * *$ & .35 & .79 \\
\hline Fit & & & $1.37(.32)$ & $4.33 * * *$ & .73 & 2.00 \\
\hline Total effect of fit on spillover effects & $\mathrm{R}^{2}$ & $F(1,57)$ & $\mathrm{B}(\mathrm{SE})$ & $T$ & LLCI & ULCI \\
\hline Fit & .69 & $121.21^{* * *}$ & $2.45(.22)$ & $11.01^{* * *}$ & 2.01 & 2.90 \\
\hline \multicolumn{7}{|l|}{ Direct effect of fit on spillover effects } \\
\hline Fit & & & $1.37(.32)$ & $4.33 * * *$ & .74 & 2.00 \\
\hline \multicolumn{7}{|l|}{ Indirect effect of fit on spillover effects } \\
\hline Trust in extension benefits & & & $1.09(.25)$ & & .66 & 1.65 \\
\hline
\end{tabular}

\section{Study 3}

\section{Method}

As with Studies 1 and 2, Study 3 used a 2 (strong vs. weak brand reputation) x 2 (high vs. low fit) x 2 (innovative vs. ordinary benefits) between-subjects experimental design with two baseline control conditions for each brand. Based on a pretest $(\mathrm{N}=51)$, we selected two watch brands, Swatch and Flik Flak, that differed in reputation strength (MSwatch = 6.97 and MFlik Flak 3.15; $\mathrm{t}(49)=8.90, p<.001$ ) and were equally well known by respondents in the UK where the study was conducted (MSwatch $=6.32$ and MFLIK Flak $=5.97 ; \mathrm{t}(61)=.77, p=\mathrm{ns})$. Pretest results $(\mathrm{N}=95)$ verified the fit of desk clock (Mhighfit $=5.81$ and 5.74; $\mathrm{t}(93)=.28, p=\mathrm{ns}$ ) and bed sheets (Mlowfit $=2.49$ and 2.34; $\mathrm{t}(93)=.47, p=\mathrm{ns}$ ) with Swatch and Flik Flak, respectively. Pretest results $(N=50)$ again validated the innovativeness of the extension benefits. For both high fit (Minnovative $=7.10$ vs. Mordinary $=3.00 ; \mathrm{t}(19)=5.24, p<.001$ ) and low fit extensions (Minnovative $=7.20$ vs. Mordinary $=3.21 ; t(27)=5.83, p<.001)$, innovative benefits were viewed as more innovative than ordinary extension benefits.

The brand extensions in Studies 1 and 2 did not contain price information. We added price information to the extension products in Study 3 to enhance ecological validity. Based on a pretest $(\mathrm{N}=52)$, we set $\$ 120$ for extensions with innovative benefits and $\$ 30$ for extensions with ordinary benefits. Pretest respondents $(N=52)$ were asked to indicate the extent to 
which they believed that the product offered good value for money $(1=$ "no value at all", "do not believe at all", $9=$ "a great deal of value", "strongly believe"; $r=.99)$. Respondents perceived the product's value for the money equally, irrespective whether they saw a brand with innovative or ordinary benefits ( $p=n s$ ). Thus value for the money was not confounded with the benefit innovativeness manipulation.

\section{Respondents and procedures}

Unless otherwise noted, Study 3's procedures and measures (see Table 1) were identical to those of Studies 1-2. As a more conservative test, however, this study was conducted over two time periods. In the first time period, 377 undergraduate students participated in the experiment. Upon entering the laboratory, respondents were randomly assigned to one of the 10 conditions. They indicated their brand familiarity and their perception of the brand's reputation. Then they read a paragraph that stated that the parent brand (either Swatch or Flik Flak) had introduced a new product to the market (either desk clock or bed sheets). Respondents indicated the extent to which they were surprised by this new brand extension. Respondents then read an excerpt detailing innovative or ordinary product benefits and rated their motivation to process the information presented in the excerpt.

The second time period occurred one week later. Two hundred seventy seven undergraduate students who had taken part in the first round participated; their data were matched with those collected in round 1 . Respondents assigned to the two control groups (Swatch/Flik Flak) were not invited back to participate in round 2. When respondents entered the laboratory, we reminded them about the prior week's task by asking them to write down any thoughts related to the new product they had read about in the previous session. Next, respondents rated the degree to which the extension's benefits were innovative in the extension category.

Respondents then evaluated the brand extension and the parent brand, and noted their trust in the brand's ability to deliver on the promised extension benefits. They also indicated the extent to which associations, which had been identified in a pretest $(\mathrm{N}=31)$ as novel to each of the parent brand's schema (i.e., relaxation and greater control of daily life), were linked with the parent brand. Next they indicated their acceptance of new brand extensions (GPS navigation system, couch, and bathroom scale) that had been identified in a pretest $(N=63)$ as low in fit with the parent brand. Finally, respondents rated brand extension fit, the excerpt's believability, and the extent to which the extension product offered value for money.

\section{Results}

\section{Manipulation and confound checks}

A set of 2 (strong vs. weak brand reputation) $\times 2$ (high vs. low fit) $\times 2$ (innovative vs. ordinary benefits) ANOVAs on the manipulation checks showed that the manipulations were successful (Table 6). There were no differences across the conditions in the brand excerpt's believability or the extension's perceived value for the money ( $p=$ ns). No other effects were observed for the confound checks (Table 6). 


\section{Brand extension evaluations}

A $2 \times 2 \times 2$ ANOVA on the measure of brand extension evaluations replicated Studies 1-2. We again observed main effects of brand reputation (Mstrong reputation = $5.24 \mathrm{vs}$. Mweak reputation =4.25; $F(1,279)=39.81, p<.001)$, fit (Mhigh fit $=5.37$ vs. Mlowfit = 4.12; F(1, 279) = 62.86, $p$ <.001), and extension benefit innovativeness (Minnovative = 6.17 vs. $M-$ ordinary $=3.32 ; F(1,279)=326.88, p<.001)$. The results revealed two-way interactions between brand reputation and fit $(F(1,279)=79.26, p<.001)$ and between brand reputation and benefit innovativeness $(F(1,279)=18.32, p<.01)$, and a significant three-way interaction $(F(1,279)=13.00, p<.001)$. More specifically, when brand reputation was strong, high and low fit extensions were equally liked by respondents (Mhighfit $=5.12$ vs. Mlowfit $=5.29 ; \mathrm{t}(137)=.47, p=\mathrm{ns}$ ), while extensions with innovative (vs. ordinary) benefits were evaluated more favorably (Minnovative $=7.01$ and Mordinary = $3.48 ; \mathrm{t}(137)=17.06, p<.001)$. When brand reputation was weak, high fit brand extensions were evaluated more positively than their low fit counterparts (Mhighfit $=5.59$ vs. Mlowfit $=2.89 ; \mathrm{t}(138)=8.80, p<.001$ ). Furthermore, the high fit extension with innovative benefits was evaluated more favorably than its low fit counterpart $(\mathrm{Ms}=7.01$ and 3.65; $t(67)=$ $8.79, p<.001$ ) and was liked more than any other weak reputation brand's extension (Table 6).

\section{Positive spillover effects}

Positive spillover effects included acceptance of novel associations linked with the parent brand (relaxation and greater control of daily life), parent brand evaluations, and acceptance of future low fit extensions (GPS navigation system, couch, and bathroom scale). A $2 \times 2 \times 2$ ANOVA on composite spillover effects showed main effects of brand reputation (Mstrong reputation $=4.57$ vs. Mweak reputation $=3.12 ; F(1,279)=295.65, p<.001)$ and extension benefit innovativeness (Minnovative $=4.84$ vs. Mordinary $=2.85 ; F(1,279)=557.82, p<.001$ ), while fit had no significant main effect (Mlow fit $=$ 3.78 vs. Mhigh fit = 3.90; $F(1,279)=1.92, p=n s)$. The results revealed two-way interactions between brand reputation and fit $(F(1,279)=88.82, p<.001)$, between brand reputation and extension benefit innovativeness $(F(1,279)=55.42, p$ $<.001)$, and between extension fit and benefit innovativeness $(F(1,279)=13.23, p<.001)$. Critically, the predicted threeway interaction between parent band reputation, extension fit, and benefit innovativeness was observed $(F(1,279)=$ 95.93, $p<.001$ ). Replicating Studies 1 and 2, for the strong reputation brand, positive spillover effects were greatest (i.e., greater than any other condition including the control condition) when the extension was low (vs. high) in fit and extension benefits were innovative (vs. ordinary) (e.g., Mlow fit-innovative6.77 vs. Mhigh fit-innovative 4.97; $\mathrm{t}(66)=10.52, p<.001$; Table 6). In contrast, for the weak reputation brand, positive spillover effects were greatest when the brand extended to a high fit product that offered innovative benefits (e.g. Mhigh fit-innovative $=4.51$ vs. Mlowfit-innovative $=3.09 ; t(67)=$ 7.33,p<.001; Table 6). 


\begin{tabular}{|c|c|c|c|c|c|c|c|c|c|c|}
\hline & \multicolumn{5}{|c|}{ Extensions to Swatch (strong brand reputation) } & \multicolumn{5}{|c|}{ Extensions to Flik Flak (weak brand reputation) } \\
\hline & $\begin{array}{l}\text { High fit/ } \\
\text { innovative } \\
\text { benefits } \\
(\mathrm{N}=38)\end{array}$ & $\begin{array}{l}\text { High fit/ } \\
\text { ordinary } \\
\text { benefits } \\
(\mathrm{N}=39)\end{array}$ & $\begin{array}{l}\text { Low fit/ } \\
\text { innovative } \\
\text { benefits } \\
(\mathrm{N}=38)\end{array}$ & $\begin{array}{l}\text { Low fit/ } \\
\text { ordinary } \\
\text { benefits } \\
(\mathrm{N}=39)\end{array}$ & $\begin{array}{l}\text { Baseline } \\
\text { control } \\
(\mathrm{N}=34)\end{array}$ & $\begin{array}{l}\text { High fit/ } \\
\text { innovative } \\
\text { benefits } \\
(\mathrm{N}=40)\end{array}$ & $\begin{array}{l}\text { High fit/ } \\
\text { ordinary } \\
\text { benefits } \\
(\mathrm{N}=40)\end{array}$ & $\begin{array}{l}\text { Low fit/ } \\
\text { innovative } \\
\text { benefits } \\
(\mathrm{N}=37)\end{array}$ & $\begin{array}{l}\text { Low fit/ } \\
\text { ordinary } \\
\text { benefits } \\
(\mathrm{N}=40)\end{array}$ & $\begin{array}{l}\text { Baseline } \\
\text { control } \\
(\mathrm{N}=32)\end{array}$ \\
\hline \multicolumn{11}{|l|}{ Manipulation checks } \\
\hline Brand reputation & $6.47^{\mathrm{a}}$ & $6.51^{\mathrm{a}}$ & $6.40^{\mathrm{a}}$ & $6.46^{\mathrm{a}}$ & $6.88^{a}$ & $3.05^{b}$ & $3.35^{\mathrm{b}}$ & $3.10^{b}$ & $3.29^{b}$ & $2.98^{b}$ \\
\hline Extension fit & $6.35^{\mathrm{a}}$ & $6.30^{\mathrm{a}}$ & $2.27^{b}$ & $1.92^{b}$ & $\mathrm{na}$ & $6.40^{\mathrm{a}}$ & $6.34^{a}$ & $2.06^{\mathrm{b}}$ & $1.60^{\mathrm{b}}$ & $\mathrm{na}$ \\
\hline Benefit innovativeness & $7.85^{\mathrm{a}}$ & $3.26^{b}$ & $7.69^{\mathrm{a}}$ & $3.33^{\mathrm{b}}$ & na & $7.61^{\mathrm{a}}$ & $3.23^{b}$ & $7.79^{\mathrm{a}}$ & $3.42^{b}$ & $\mathrm{na}$ \\
\hline \multicolumn{11}{|l|}{ Confounds } \\
\hline Brand excerpt believability & $7.33^{\mathrm{a}}$ & $7.51^{2}$ & $7.37^{\mathrm{a}}$ & $7.14^{\mathrm{a}}$ & na & $7.39^{a}$ & $7.57^{2}$ & $7.30^{\circ}$ & $7.67^{2}$ & na \\
\hline Extension value for money & $6.58^{\mathrm{a}}$ & $6.24^{3}$ & $6.91^{2}$ & $6.16^{2}$ & $\mathrm{na}$ & $6.72^{2}$ & $6.45^{\mathrm{a}}$ & $6.83^{\mathrm{a}}$ & $6.32^{2}$ & na \\
\hline \multicolumn{11}{|l|}{ Dependent variables } \\
\hline Extension evaluations & $6.71^{\mathrm{a}}$ & $3.61^{\mathrm{b}}$ & $7.29^{\mathrm{a}}$ & $3.35^{\mathrm{b}}$ & $\mathrm{na}$ & $7.01^{\mathrm{a}}$ & $4.13^{b}$ & $3.65^{b}$ & $2.19^{\circ}$ & $\mathrm{na}$ \\
\hline Composite spillover effects & $4.97^{b}$ & $3.49^{\text {de }}$ & $6.77^{\mathrm{a}}$ & $3.03^{e}$ & $3.85^{\mathrm{d}}$ & $4.51^{c}$ & $2.63^{\text {fg }}$ & $3.09^{\circ}$ & $2.24^{\mathrm{g}}$ & $2.78^{\mathrm{ef}}$ \\
\hline Novel parent brand associations & $3.80^{\mathrm{b}}$ & $2.45^{\text {de }}$ & $6.23^{\mathrm{a}}$ & $2.03^{\circ}$ & $2.77^{\mathrm{d}}$ & $4.06^{b}$ & $2.13^{\text {de }}$ & $2.82^{\text {od }}$ & $2.36^{\mathrm{de}}$ & $2.55^{\mathrm{de}}$ \\
\hline Parent brand evaluations & $6.73^{\mathrm{b}}$ & $5.29^{\mathrm{d}}$ & $8.24^{\mathrm{a}}$ & $4.28^{\text {de }}$ & $5.38^{\circ}$ & $5.28^{\text {ed }}$ & $3.44^{e}$ & $3.65^{\circ}$ & $2.17^{f}$ & $3.42^{e}$ \\
\hline Acceptance of future extensions & $4.50^{b}$ & $2.71^{\text {od }}$ & $5.86^{\mathrm{a}}$ & $2.77^{d}$ & $3.43^{\circ}$ & $4.20^{b}$ & $2.33^{\mathrm{d}}$ & $2.79^{\mathrm{pd}}$ & $2.20^{\mathrm{d}}$ & $2.38^{\mathrm{d}}$ \\
\hline \multicolumn{11}{|c|}{ Variables relevant to theunderlying logic of hypotheses } \\
\hline Trust in extension benefits & $6.14^{\mathrm{a}}$ & $6.41^{\mathrm{a}}$ & $5.89^{\mathrm{a}}$ & $5.96^{\mathrm{a}}$ & $\mathrm{na}$ & $3.93^{b}$ & $3.83^{b}$ & $2.26^{\circ}$ & $2.44^{\circ}$ & na \\
\hline Extension surprise & $3.22^{\mathrm{b}}$ & $3.36^{\mathrm{b}}$ & $7.53^{\mathrm{a}}$ & $7.51^{\mathrm{a}}$ & na & $3.16^{b}$ & $3.27^{\mathrm{b}}$ & $7.60^{\mathrm{a}}$ & $7.51^{\mathrm{a}}$ & na \\
\hline Motivation to process & $4.35^{\mathrm{b}}$ & $4.06^{b}$ & $7.61^{\mathrm{a}}$ & $7.17^{\mathrm{a}}$ & $\mathrm{na}$ & $4.74^{b}$ & $4.58^{b}$ & $7.56^{\mathrm{a}}$ & $7.35^{\mathrm{a}}$ & $\mathrm{na}$ \\
\hline
\end{tabular}

Means with different superscripts are significantly different, $p<.05$; Bold-faced means show successful manipulation checks or support for our hypotheses.

\section{Mediation analyses}

A set of $2 \times 2 \times 2$ ANOVAs on surprise about the brand extension, motivation to process extension benefits, and trust in the parent brand's ability to deliver the promised extension benefits also replicated the findings of Studies 1 and 2 . For the strong reputation brand, motivation to process mediated the influence of fit on positive spillover effects. When the strong reputation brand offered innovative extension benefits, low fit enhanced motivation to process extension benefit information $(\mathrm{B}=-3.28, \mathrm{SE}=.21, \mathrm{t}=-15.51, p<.001,95 \% \mathrm{Cl}-3.70$ to -2.86$)$, which in turn strengthened spillover effects ( $\mathrm{B}$ $=.44, \mathrm{SE}=.10, \mathrm{t}=4.66, p<.001,95 \% \mathrm{Cl} .25$ to .63 ). Detailed results of the total, direct, and indirect effects (via motivation to process) of fit on the reputable brand's spillover effects are reported in Table 7A. As in Studies 1 and 2, trust did not mediate the relationship between low fit and the spillover effects.

In line with Studies 1 and 2, for the weak reputation brand with innovative extension benefits, trust was a significant mediator in the relationship between fit and spillover effects. Specifically, for such extension, fit increased trust in the parent brand's ability to deliver promised extension benefits reliably $(\mathrm{B}=1.67, \mathrm{SE}=.21, \mathrm{t}=7.87, p<.001,95 \% \mathrm{Cl} 1.25$ to 2.10), which in turn positively influenced spillover effects $(B=.84, \mathrm{SE}=.07, \mathrm{t}=13.09, p<.001,95 \% \mathrm{Cl} .72$ to .97$)$. Table 7B lists the detailed results of the total, direct, and indirect effects (via trust) of fit on the spillover effects for the weak reputation brand. In accord with Studies 1 and 2, motivation to process did not mediate the effect of low fit on spillover effects when brand reputation is weak.

\section{Discussion}

Study 3 fully replicates Studies 1-2 using a different pair of parent brands, reversing the high and low fit extension product categories, using delayed measures to assess spillover effects, and including extension product price information. 


\section{General discussion}

We propose that firms may synergistically pursue brand growth opportunities by introducing brand extensions that yield multiple positive effects; they create favorable brand extension evaluations and induce positive spillover effects (they add novel associations to the parent brand schema, enhance evaluations of the parent brand, and increase consumers' acceptance of future brand extensions). Although several tactics may induce these effects, we examine: (a) the extent to which the brand has a strong (vs. a weak) reputation, (b) the extent to which the brand extension is low (vs. high) in fit with the parent brand, and (c) the extent to which it offers innovative (vs. ordinary) benefits in the extension category.

Across three studies, we find converging evidence that brands with weak vs. strong reputation should pursue distinct brand growth strategies involving high or low fit extensions with innovative benefits. A brand with a strong reputation is better off from a growth perspective using a low fit extension with innovative benefits. Indeed when a parent brand has a strong reputation, using either low or high fit brands with innovative benefits enhances extension evaluations. However, only the low fit extension with innovative benefits leads to the greatest spillover effects. Why? We surmise that when brand reputation is strong, incongruity derived from low fit induces surprise and enhances consumers' motivation to process brand extension information, such that innovative benefits are more deeply appreciated. Because of the limited overlap between the low fit extension and the parent brand, the parent brand is now seen as different and likeable.

However, from a growth perspective, brands with weak reputation are better off when they rely on a high (vs. low) fit extension with innovative benefits. The high fit extension (due to high overlap in skills and competence with the parent brand) alleviates trust problems associated with the weak reputation brand's ability to deliver innovative benefits. In addition to the mediating process by trust, fit also has a direct effect on the weak reputation parent brand's spillover effects. High fit enhances consumers' comfort with the brand extension and reduces uncertainty (Smith \& Andrews, 1995), which also facilitates the weak reputation brand's schema revision when its extensions possess innovative benefits.

In sum, our findings suggest two distinct brand growth strategies; one for brands with a strong reputation (involving low fit and innovative benefits) and a different one for brands with a weak reputation (involving high fit and innovative benefits). These novel findings are noteworthy and should be pursued in future work.

Notably, the managerial impact of strong reputation brands with low fit and innovative benefits is potentially compelling. A firm with a strong reputation may decide not to introduce a new low fit extension that offers innovative benefits because it fears a negative impact of low fit on the extension product as well as the parent brand. Instead, it may introduce the new product under an individual brand name. This conservative approach may be costly in the short run because using an individual brand name (vs. a brand extension) would entail higher promotion costs. It may also entail high opportunity costs in the long run, as the firm would miss the opportunity to induce strong positive spillover effects and grow the brand through the noted extension strategy. 


\section{Limitations and future research}

Milberg et al. (2010) found that the fit-extension relationship was less robust when participants were exposed to information regarding competitors. Extensions perform better regardless of fit when paired with relatively unfamiliar competitors (see also Milberg et al., 2013). We wonder whether our findings would be replicated when the extension scenarios are placed in a competitive context. On the one hand, innovative benefits already take competition into consideration; by definition innovative benefits are new to the product category and not offered by competing alternatives. Moreover, strong reputation brands are familiar to consumers, suggesting that competitor information may not have significant impact. Therefore, the spillover effects found in the present research may still hold even in a competitive context. On the other hand, if and when highly familiar competing alternatives greatly reduce consumers' perceived risk more than the focal extension does, the positive spillover effect on the parent brand may be weaker than those we observed. This empirical question deserves attention from future research.

Additional work might consider how various levels of fit and benefit innovativeness impact the results. For example, operationally, our "high fit" brand extensions were relatively moderate in fit. Considering the conflicting results about the evaluations of moderate and high extensions (Boush \& Loken, 1991; Meyers-Levy \& Tybout, 1989), future research might examine whether our results differ when fit is extremely high. Similarly, we examined only innovative versus ordinary benefits. It remains to be seen whether the impact of benefit innovativeness has linear or non-linear effects on the dependent variables we studied. Furthermore, we invite additional work that confirms and expands on the process results we observed. For example, future research might manipulate processing motivation to verify whether heightened motivation to process the extension benefits indeed drives the effect of low fit on the spillover effect for the strong reputation brands. Additionally, future research may test the relative weight consumers put on (the diagnosticity of) the brand extension information versus prior beliefs about the parent brand.

We find that when innovative extension benefits are incorporated into the parent brand schema, consumers will accept other low fit extensions as part of the parent brand more readily. One wonders if the initial extension creates more broadened associations with the parent brand, thus making other low fit extensions seem closer to the parent brand in fit. A small-scale, post hoc experiment $(N=88)$ offers preliminary support for this argument. This experiment asked respondents to read the same low fit-innovative benefit scenario used in Study 1, using Lenovo as the focal brand. Results showed that respondents accepted new low fit extensions (sunglasses, couches, compact air purifiers) more readily than respondents in the control condition ( $\mathrm{Ms}=6.45$ and 2.17 , respectively; $\mathrm{t}(86)=16.34, p<.001)$. They also saw these new extensions as somewhat higher in fit with the parent brand $(\mathrm{Ms}=2.48$ and 1.91 , respectively; $\mathrm{t}(86)=3.80, p<.01)$. Alternative explanations are, however, possible given a relatively small increase in the perceived fit rating. Perhaps broadened associations linked to the brand schema minimize the role of fit such that consumers are more accepting of a brand's future extensions without considering fit. Or perhaps the initial extension strengthens brand reputation to the extent that more weight is given to the brand's reputation versus fit in evaluating future extensions. Future research should examine these issues. 
Future research might also investigate the minimum level of novelty and usefulness that extension benefits must offer to produce positive brand extension evaluations and spillover effects. Also, although innovative products should be both novel and useful, are there conditions where spillover effects are observed when only one of the two components of innovativeness (novelty and usefulness) is high?

Finally, our results show that low fit extensions with ordinary benefits reduce parent brand liking. This dilution effect was observed for both weak and strong reputation brands. To what extent does consumer disappointment, increased cynicism (a brand as seen as simply wanting to cash out by leveraging its brand as much as possible), reduced brand trust, or a combination of these help explain consumer backlash to low fit extensions with ordinary benefits? Although these questions are beyond the scope of the present research, they are worthy of future work.

\section{Appendix A. Supplementary data}

Supplementary data to this article can be found online at http://dx.doi.org/10.1016/jicps.2014.12.003.

\section{References}

Aaker, D. A., \& Keller, K. L. (1990). Consumer evaluations of brand extensions. Journal of Marketing, 54, $27-41$.

Aaker, J. L., Garbinsky, E. N., \& Vohs, K. D. (2012). Cultivating admiration in brands: Warmth, competence, and landing in the "golden quadrant". Journal of Consumer Psychology, 22, 191-194.

Ahluwalia, R. (2008). How far can a brand stretch? Understanding the role of self-construal. Journal ofMarketing Research, 45, 337-350.

Ahluwalia, R., \& Gürhan-Canli, Z. (2000). The effects of extensions on the family brand name: An accessibility-diagnosticity perspective. Journal of Consumer Research, 27, 371-381.

Balachander, S., \& Ghose, S. (2003). Reciprocal spillover effects: A strategic benefit of brand extensions. Journal of Marketing, 67, 4-13.

Barone, M. J. (2005). The interactive effects of mood and involvement on brand extension evaluations. Journal of Consumer Psychology, 15, 263-270. Barone, M. J., \& Jewell, R. D. (2013). The innovator's license: A latitude to deviate from category norms. Journal of Marketing, 77, 120-134. Barsalou, L. W. (1991). Deriving categories to achieve goals. In G. H. Bower (Ed.), The psychology of learning and motivation (pp. 1-58). New York, NY: Academic.

Boush, D. M., \& Loken, B. (1991). A process-tracing study of brand extension evaluation. Journal of Marketing Research, 28, 16-28.

Broniarczyk, S. M., \& Alba, J. W. (1994). The importance of the brand in brand extension. Journal of Marketing Research, 31, 214-228.

Burroughs, J. E., Dahl, D. W., Moreau, C. P., Chattopadhyay, A., \& Gorn, G. J. (2011). Facilitating and rewarding creativity during new product development. Journal of Marketing, 75, 53-67.

Cutright, K. M., Bettman, J. R., \& Fitzsimons, G. J. (2013). Putting brands in their place: How a lack of control keeps brands contained. Journal of Marketing Research, 50, 365-377.

Goldenberg, J., Mazursky, D., \& Solomon, S. (1999). Toward identifying the inventive templates of new products: A channeled ideation approach. Journal of Marketing Research, 36, 200-210.

Hayes, A. F. (2012). Process: A versatile computational tool for observed variable mediation, moderation, and conditional process modeling [white paper]. (Retrieved October 10, 2013 from) http://www.afhayes.com/public/ process2012.pdf

Huffman, C., \& Houston, M. J. (1993). Goal-oriented experiences and the development of knowledge. Journal ofConsumer Research, 20, 190-207. John, D. R., Loken, B., \& Joiner, C. (1998). The negative impact ofextensions: Can flagship products be diluted? Journal of Marketing, 62, 19-32. 
Kim, H., \& John, D. R. (2008). Consumer response to brand extensions: Construal level as a moderator of the importance of perceived fit. Journal of Consumer Psychology, 18, 116-126.

Klink, R. R., \& Smith, D. C. (2001). Threats to the external validity of brand extension research. Journal of Marketing Research, 38, 326-335.

Loken, B., \& John, D. R. (1993). Diluting brand beliefs. When do brand extensions have a negative impact? Journal of Marketing, 57, 71-84.

Maoz, E., \& Tybout, A. M. (2002). The moderating role of involvement and differentiation in the evaluation of brand extensions. Journal of Consumer Psychology, 12, 119-131.

Meyers-Levy, J., \& Tybout, A. M. (1989). Schema congruity as a basis for product evaluation. Journal of Consumer Research, 16, 39-54.

Meyvis, T., Goldsmith, K., \& Dhar, R. (2012). The importance ofthe context in brand extension: How pictures and comparisons shift consumers' focus from fit to quality. Journal of Marketing Research, 49, 206-217.

Milberg, S. J., Park, C. W., \& McCarthy, M. S. (1997). Managing negative feedback effects associated with brand extensions: The impact of alternative branding strategies. Journal of Consumer Psychology, 6(2), 119-140.

Milberg, S. J., Sinn, F., \& Goodstein, R. C. (2010). Consumer reactions to brand extensions in a competitive context: Does fit still matter? Journal of Consumer Research, 27, 543-553.

Milberg, S. J., Goodstein, R. C., Sinn, F., Cuneo, A., \& Epstein, L. D. (2013). Call back the jury: Reinvestigating the effects of fit and parent brand quality in determining brand extension success. Marketing Management, 29, 374-390.

Monga, A. B., \& John, D. R. (2010). What makes brands elastic? The influence of brand concept and styles of thinking on brand extension evaluation. Journal of Marketing, 74, 80-92.

Moreau, P. C., \& Dahl, D. W. (2005). Designing the solution: The impact of constraints on consumers' creativity. Journal of ConsumerResearch, 32,13-22.

Morrin, M. (1999). The impact of brand extensions on parent brand memory structures and retrieval processes. Journal of Marketing Research, 36, 517-525.

Park, C. W., Milberg, S., \& Lawson, R. (1991). Evaluation of brand extensions: The role of product feature similarity and brand concept consistency. Journal of Consumer Research, 18, 185-193.

Park, C. W., Jun, S. Y., \& Shocker, A. D. (1996). Composite branding alliances: An investigation of extension and feedback effects. Journal of Marketing Research, 33, 453-466.

Park, C. W., Eisingerich, A. B., \& Park, J. W. (2013). Attachment-aversion (AA) model ofcustomer-brand relationships. Journal of Consumer Psychology, 23, 229-248.

Schützwohl, A. (1998). Surprise and schema strength. Journal of Experimental Psychology: Learning, Memory, and Cognition, 24, 1182-1199.

Sellier, A. L., \& Dahl, D. W. (2011). Focus! Creative success is enjoyed through restricted choice. Journal ofMarketing Research, 48, 996-1007.

Smith, D. C., \& Andrews, J. (1995). Rethinking the effect of perceived fit on customers' evaluations of new products. Journal of the Academy of Marketing Science, 23, 4-14.

Smith, D. C., \& Park, C. W. (1992). The effects of brand extensions on market share and advertising efficiency. Journal of Marketing Research, 29, 296-313.

Sternberg, R. J., \& Lubart, T. I. (1999). The concept of creativity: Prospects and paradigms. In R. J. Sternberg, \& T. I. Lubart (Eds.), Handbook of creativity (pp. 3-15). New York, NY: Cambridge University Press.

Sujan, M., \& Bettman, J. R. (1989). The effects of brand positioning strategies on consumers' brand and category perceptions: Some insights from schema research. Journal ofMarketing Research, 26, 454-467.

Sullivan, M. (1990). Measuring image spillovers in umbrella-branded products. Journal of Business, 63, 309-329. 
Völckner, F., \& Sattler, H. (2006). Drivers of brand extension success. Journal of Marketing, 70, 18-34. 